\title{
Pressure Gradient Effects on Hypersonic Cavity Flow Heating
}

\author{
Joel L. Everhart ${ }^{*}$, Stephen J. Alter ${ }^{\dagger}$, N. Ronald Merski ${ }^{\ddagger}$, William A. Wood ${ }^{\S}$ \\ NASA Langley Research Center, Hampton, VA, 23681 \\ and \\ Ramadas K. Prabhu ${ }^{* *}$ \\ Lockheed Martin Engineering \& Sciences Co., Hampton, VA, 23681
}

\begin{abstract}
The effect of a pressure gradient on the local heating disturbance of rectangular cavities tested at hypersonic freestream conditions has been globally assessed using the two-color phosphor thermography method. These experiments were conducted in the Langley 31-Inch Mach 10 Tunnel and were initiated in support of the Space Shuttle Return-To-Flight Program. Two blunted-nose test surface geometries were developed, including an expansion plate test surface with nearly constant negative pressure gradient and a flat plate surface with nearly zero pressure gradient. The test surface designs and flow characterizations were performed using two-dimensional laminar computational methods, while the experimental boundary layer state conditions were inferred using the measured heating distributions. Three-dimensional computational predictions of the entire model geometry were used as a check on the design process. Both open-flow and closed-flow cavities were tested on each test surface. The cavity design parameters and the test condition matrix were established using the computational predictions. Preliminary conclusions based on an analysis of only the cavity centerline data indicate that the presence of the pressure gradient did not alter the open cavity heating for laminar-entry/laminar-exit flows, but did raise the average floor heating for closed cavities. The results of these risk-reduction studies will be used to formulate a heating assessment of potential damage scenarios occurring during future Space Shuttle flights.
\end{abstract}

\section{Nomenclature}

\begin{tabular}{|c|c|}
\hline$B F$ & Bump Factor \\
\hline$B F_{\max }$ & maximum Bump Factor on the cavity end wall \\
\hline$C_{p}$ & pressure coefficient \\
\hline$h$ & heat transfer coefficient, $h=q /\left(H_{a w}-H_{w}\right),\left(l b m / f t^{2} / s\right)$ \\
\hline$H$ & enthalpy (btu/lbm) \\
\hline$L, W, H$ & cavity length, width, and depth (in) \\
\hline$M$ & Mach number \\
\hline$p$ & pressure (psi) \\
\hline$q$ & surface heat transfer rate $\left(\mathrm{btu} / \mathrm{ft}^{2} / \mathrm{s}\right)$ \\
\hline$R n$ & model reference nose radius (in) \\
\hline $\operatorname{Re}$ & unit Reynolds number $(1 / f t)$ \\
\hline $\operatorname{Re}_{\theta}$ & momentum thickness Reynolds number \\
\hline
\end{tabular}

This material is declared a work of the U.S. Government and is not subject to copyright protection in the United States.

* Aerospace Engineer, Aerothermodynamics Branch, Mail Stop 408A, Associate Fellow AIAA.

Aerospace Engineer, Aerothermodynamics Branch, Mail Stop 408A, Senior Member AIAA.

* Branch Head, Aerothermodynamics Branch, Mail Stop 408A, Associate Fellow AIAA.

$\S$ Aerospace Engineer, Aerothermodynamics Branch, Mail Stop 408A, Senior Lifetime Member AIAA.

** Aerospace Engineer, Langley Program Office, Mail Stop 408A. 


$\begin{array}{ll}R T F & \text { Return-to-Flight } \\ s & \text { distance along the streamline (ft) } \\ T & \text { temperature ( } R \text { ) } \\ t & \text { time (s) } \\ T G P & \text { thermographic phosphor } \\ U & \text { velocity magnitude (ft/s) } \\ x & \text { axial distance from model leading edge (in) } \\ y & \text { spanwise distance from model centerline (in) } \\ z & \text { distance normal to } x \text {-y plane (in) } \\ \alpha & \text { angle-of-attack (deg) } \\ \gamma & \text { ratio of specific heats } \\ \delta & \text { boundary layer thickness (in) } \\ \theta & \text { boundary layer momentum thickness (in) } \\ \Theta & \text { Normalized temperature in heating equation } \\ \Lambda & \text { Normalized time in heating equation } \\ \rho & \left.\text { density (lbm/ft }{ }^{3}\right) \\ \text { Subscripts } & \\ \infty & \text { freestream static conditions } \\ \text { avg } & \text { average } \\ \text { aw } & \text { adiabatic wall conditions } \\ F R & \text { conditions from Fay-Riddell calculation for a hemisphere } \\ \text { local } & \text { local condition } \\ r e f & \text { reference condition } \\ T 1 & \text { reservoir conditions } \\ T 2 & \text { stagnation conditions behind a normal shock } \\ w & \text { wall conditions }\end{array}$

\section{Introduction}

The Final Report of the Columbia Accident Investigation Board (CAIB) was released in August 2003. The CAIB identified "a breach in the Thermal Protection System of the leading edge of the left wing, caused by a piece of insulating foam ..." as the probable event resulting in the loss of the Space Shuttle Columbia during flight STS-107 on February 1, 2003. Many possibilities were investigated prior to reaching this assessment, among them the creation of impact-induced cavities in the thermal protection system (TPS) tiles, resulting in local augmentation of the heating and eventual burn through of the aluminum substructure. Though impact-induced damage to the tiles was eventually excluded as the cause of the Columbia accident, the CAIB recommended that NASA "Develop, validate, and maintain physics-based computer models to evaluate Thermal Protection System damage from debris impacts. These tools should provide realistic and timely estimates of any impact damage from possible debris from any source that may ultimately impact the Orbiter. Establish impact damage thresholds that trigger responsive corrective action, such as on-orbit inspection and repair, when indicated." Langley Research Center, operating in concert with the Shuttle Accident Investigation Team and the Return-To-Flight Program, has provided an experimental cavity heating database of nearly 775 wind tunnel runs, along with many computational simulations, of this complex fluid dynamic and aeroheating environment for analysis and modeling by the Damage Assessment Aeroheating Team at Johnson Space Center. The predominance of these data and simulations are for non-surfacebreaching, impact damage situations where near-zero pressure gradients occur, such as on the windward surface tile acreage. Because of the fast pace of this effort, most of these results are only in the earliest stages of reporting and, accordingly, are not readily available to the general community at this time. The purpose of this paper is to present one aspect of this effort; that is the impact on local heating augmentation of an expanding flow, resulting in a negative pressure gradient, over a cavity damage site. Based on the outcome of the analysis, allowances for these effects may be required in the engineering modeling tools currently being developed to assess potential heating augmentation resulting from damaged surfaces. Results from these analyses directly impact the go/no-go decision required prior to any spacewalk tile repair mission performed by the shuttle crew. 


\section{Literature Assessment}

The supersonic/hypersonic cavity flow literature (particularly that for laminar test conditions), while helpful, is particularly sparse on both the local and downstream effects of many fundamental flow parameters. Fletcher, et al. published the survey paper "A Review of Heat Transfer in Separated and Reattached Flows" in 1970. Nestler updated this survey with more recent work in 1985 in "The Effects of Surface Discontinuities on Convective Heat Transfer in Hypersonic Flow." Together, these papers include much of the existing, pertinent cavity flow literature. They cited theoretical models of cavity flow developed by Burggraf (1965), Chapman (1956), Carlson (1959), Chang (1966), and Lamb (1967); however, none of the theories adequately capture the physics of laminar and turbulent three-dimensional cavity flows as will be demonstrated via global surface heating distributions presented herein, though they offer a framework for experimental studies. Numerical studies were conducted by Adams (1974), Morgenstern and Chokani (1994), Zhang, et al. (2001), and more recently for the CAIB and the Shuttle RTF program by Wood, et al. (2004) and Pulsonetti, et al. (2005). The computational work presented by Wood uses the previously mentioned unpublished RTF experimental open cavity results for CFD comparison and validation of the numerical modeling, while Pulsonetti's work deals with flight traceability. Experimentally, laminar two-dimensional flows were addressed by Galenter (1975) and Nestler (1966); laminar axisymmetric flows were addressed by Nestler (1970), Nicoll (1963, 1964), and Wyborny, et al. (1967); and, laminar three-dimensional flows were examined by Cheatwood, et al. (2001), Hahn (1969), and Nestler (1981). Experimental studies with cavities tested in transitional boundary layers or to determine the onset of transition were presented by Charbonnier and Boerrigter (1993), Boerrigter and Charbonnier (1996), Hollis and Liechty (2002, 2006), Larson and Keating (1960), Liechty, et al. (2006a), and Rhudy and Magnan (1964). Turbulent two-dimensional experiments were presented by Charwat, et al. (1961a, 1961b), Chin and Seban (1972), Emery (1969), Hunt (1977), Lamb (1968, 1980a, 1980b), Nestler (1968, 1969, 1970a, 1970b), Shchukin, et al. (1980), and Stallings and Wilcox (1987); turbulent axisymmetric experiments were conducted by Hunt (1974) and Netterfield (1989); and turbulent three-dimensional experiments were published by Wilcox $(1990,1991)$. In general, the heating measurements were obtained with sparsely-spaced discrete sensors, the exception being those global phosphor thermography measurements presented by Cheatwood, et al., and Hollis and Liechty for circular cavities. Because of this spatial measurement sparseness, much of the three-dimensional nature of the surface heating profile is missed, as is in many cases the important peak heating value. While most of the idealized cavity geometries are rectangular with a flat bottom profile (a few have an arc bottom), the paper by Emery is of particular significance because heating profiles are presented for models with notched, cutback profile geometries that may be more representative of potential impact damage conditions. Two papers by Blair and Stallings (1986) and Stallings, et al. (1991) are significant because they present oil flow visualizations in and around the cavity and vapor screen visualizations of the cavity crossflow plane, clearly showing the growth and development of the cavity vortex structure. The important class of cavities known as gaps (i.e., cavities with lengthto-depth ratio less than 1) has been examined by Coats, et al. (1970), Johnson (1973), Throckmorton (1974), and Weinstein, et al. (1975).

As demonstrated above, a large amount of cavity research studies are available in the published literature. However, there exists only a limited amount of laminar flow experimental data for evaluating heating effects in supersonic/hypersonic cavities, and most of the existing parametric variations and correlations have been developed using turbulent heating measurements. Further, turbulent methods have typically been used for thermal assessments of damage on the Space Shuttle, even though much of the re-entry trajectory provides laminar edge conditions on the vehicle. The use of these turbulent methods may be overly conservative for the laminar conditions.

No evidence of the effect of pressure gradient on the heating was found in the literature. An objective of the present study is to provide sufficient cavity heating data to assess the effects of pressure gradient under laminar entry flow conditions. Specifically, the focused objective is to address the binary yes-no question of whether pressure gradient is an important flow parameter for cavity damage. A secondary objective is to provide enhanced surface heating information under controlled conditions to the CFD community for flow simulation studies.

\section{Supersonic/Hypersonic Cavity Flow Physics}

Based on the literature survey, the following overview of cavity flow physics is presented. Length-to-depth ratio is typically used to distinguish between and classify different cavity flow regimes, as depicted in Figure 1. Very short or deep cavities with $\mathrm{L} / \mathrm{H}<1$ are known as gaps. In this case, shearing induced by the main stream flow causes the development of a column of counter-rotating vortices within the gap numbering approximately $\mathrm{H} / \mathrm{L}$. Alternating hot spots are developed in the gap when the vortices directionally align and impinge on the sidewall. Two stable flow conditions exist for cavities with length $\mathrm{L} / \mathrm{H}>1$. The first is a short cavity in the length range $1<\mathrm{L} / \mathrm{H}<10$, 
known as an open cavity in the literature. The mainstream flow does not enter the cavity directly, though there may be some mass interchange with the low-energy vortical flow inside the cavity. In this case, the pressure in the cavity is typically above the ambient and climbs to a peak at the downstream lip. The heating drops to values significantly below the undisturbed value and rises slowly to a peak value on the downstream lip. The other stable solution is a long cavity, also known as a closed cavity, with length $\mathrm{L} / \mathrm{H}>14$. In this case, three distinct flows may develop if the cavity is long enough. First, the upstream flow is able to turn into the cavity and impinge on the floor, creating an aft-facing-step flow field. Next, a boundary layer on the floor may develop and recover to the ambient level outside the cavity. Finally, as the flow approaches the end wall it will turn outward and create a forward-facing-step flow field. For long, deep cavities, the pressure gradients may be severe where the flow turns and strong expansion and shock waves will be generated. Viscous shearing generated by this flow turning will augment the heating to levels significantly higher than the ambient levels on both the cavity floor and the end wall. The pressure in these long cavities will decrease below the ambient and steadily increase downstream, reaching large values of over-pressure behind the shocks. Vortices will develop on the cavity sidewalls as the flow expands around the corner into the cavity and on the floor after flow impingement, further augmenting the heating, which may extend laterally around the cavity in the most severe cases. These vortices will interact with the cavity end wall and spill into the downstream region beyond the cavity. Given laminar inflow, analysis of the heating profiles indicates that most any type of outflow may occur, depending on the cavity and its environmental state. The in-cavity flow may remain laminar, become transitional, or transition to fully turbulent flow; the downstream possibilities are equally varied and are currently the subject of extensive analysis and testing (Liechty 2006a) in support of Shuttle RTF. Cavities in the range $10<\mathrm{L} / \mathrm{H}<14$ are typically unsteady as the flow alternates between the two bounding conditions; these are known as transitional cavities. Transitional cavities are avoided where possible in the present tests because of the complexity of the required instrumentation and test time necessary to address flow steadiness.

The boundaries between the different cavity flow regimes are nominal, at best. For example, different researchers have measured $\mathrm{L} / \mathrm{H}$ values ranging from 9 to 11 as the upper limit for open cavities and from 12 to 15 as the lower limit for closed cavity flow. These limits should therefore be taken only as a guide. Also, it is important to note that most of the reported cavity data were acquired in air $(\gamma=1.4)$ with some in helium $(\gamma=1.67)$. Since turning angle is a function of both Mach number and $\gamma$, it is conceivable that the open/closed cavity boundaries will vary during re-entry as vehicle boundary layer edge conditions change. At present, experimental data are insufficient to estimate the strength of this effect on the aeroheating.

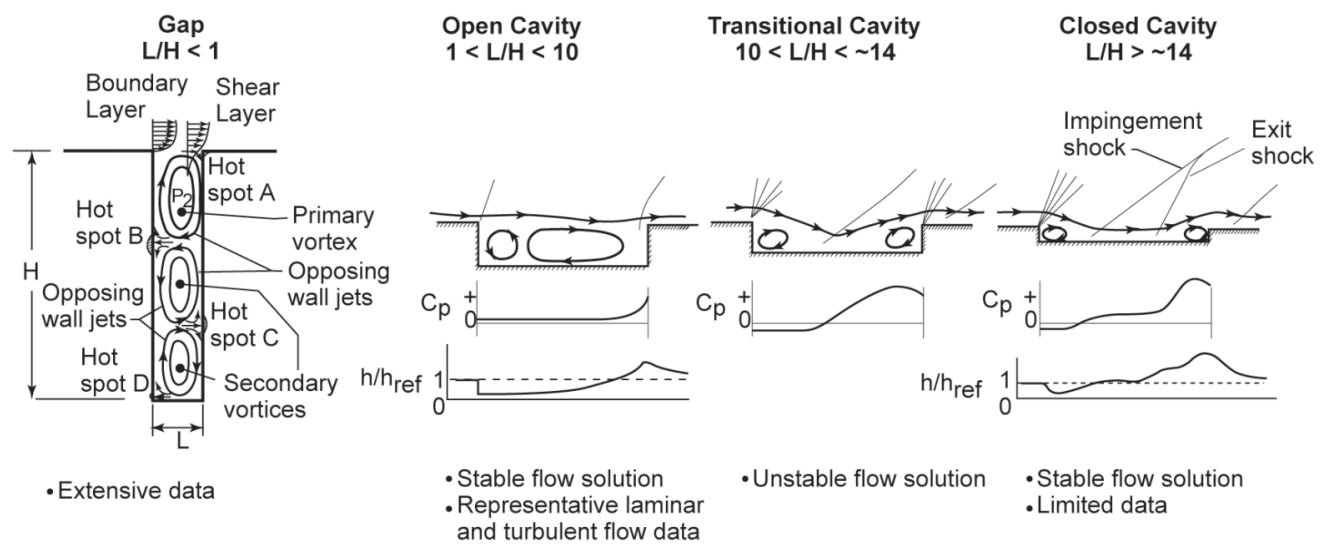

Figure 1.- Cavity flow regimes.

\section{Establishing the Testing Environment}

When few (if any) direct measurements of the cavity geometry are available and when the exact location of the cavity (implying local flow conditions) is unknown, defining the heating environment of a damage-scenario cavity presents a significant challenge. Many possible variables and parameters exist. Following the literature, the gross geometric parameter space includes: length (L), width (W), and depth (H), and planform, cross-sectional, and profile variations. Sidewall and upstream end-wall entry angles may play an important role on the flow expansion into the cavity, while sidewall and end-wall exit angles may affect recompression on the downstream wall and further expansion around the end-wall corner - all parameters having a direct influence on the heating. The depth distribution along the cavity profile may potentially affect how or if the flow enters the cavity and impinges on the 
floor. The impact of roughness caused by irregular surfaces, protuberances, gap fillers between tiles (present or missing), embedded objects, etc. in and upstream of the cavity is unknown, but the roughness may significantly impact the shear layer/boundary layer transition process (Liechty, et al. 2006b). Local flow conditions and parameters include boundary layer thickness $(\delta)$ and momentum thickness $(\theta)$, edge Mach number $\left(\mathrm{M}_{\mathrm{e}}\right)$, momentum thickness Reynolds number $\left(\operatorname{Re}_{\theta}\right)$, stream direction with respect to the cavity major axis, chemistry effects reflected in the ratio of specific heats $(\gamma)$, wall temperature ratio $\left(T_{w} / T_{a w}\right)$, boundary layer state (laminar, transitional, or turbulent) entering/leaving the cavity, and, of course, pressure gradient.

Representative surface flow conditions for the Shuttle Orbiter (Reuther, et al. 2004) have been computed using the DPLR code (Wright, et al. 1998) for the STS-107 re-entry trajectory. Sample conditions from the trajectory computations are presented in Table 1 for nominal altitudes of 243,000 ft (Mach 25) and 201,767 ft (Mach 18). Three windward surface streamlines spanning the chine region of the wing are presented in Fig. 2a and Fig. 2b, pressure coefficients are presented in Fig. 2c and Fig. 2d, pressure gradient distributions are presented in Fig. 2e and Fig. 2f, and local Mach number and local momentum thickness Reynolds number are presented in Fig. $2 \mathrm{~g}$ and Fig. $2 \mathrm{~h}$, and Fig. $2 \mathrm{i}$ and Fig. $2 \mathrm{j}$, respectively. The location of the wing leading edge is most readily apparent in the pressure gradient as the sharp negative peak that occurs at approximately 36,49 , and 67 feet for streamlines 1,2 , and 3 , respectively. Immediately aft of the leading edge, a representative $\mathrm{dC}_{\mathrm{p}} / \mathrm{ds}$ value of about -0.15 per foot (-0.013 per inch) occurs on the chine. Edge Mach numbers are in the range 2.5 to 2.9. Momentum thickness Reynolds number ranges are 80 to 130 for CFD Case 1 and 220 to 340 for CFD Case 6. Therefore, these target conditions are selected as representative for designing the experiment. Note, again, that the objective is not to match surface conditions exactly, but to assess the effects of pressure gradient at conditions representative of those on the surface.

Table 1.- Selected STS-107 trajectory conditions for CFD modeling.

\begin{tabular}{|c|c|c|c|c|c|c|c|}
\hline $\begin{array}{c}\text { CFD } \\
\text { Case. }\end{array}$ & $\begin{array}{c}\text { Altitude } \\
(\mathbf{f t})\end{array}$ & $\begin{array}{c}\text { Velocity } \\
(\mathbf{f t} / \mathbf{s})\end{array}$ & $\begin{array}{c}\text { Density } \\
\left.\mathbf{( l b / f t}^{\mathbf{3}}\right)\end{array}$ & $\begin{array}{c}\text { Temp } \\
\left.\mathbf{(}^{\mathbf{O}} \mathbf{R}\right)\end{array}$ & $\begin{array}{c}\text { Mach } \\
\text { Number }\end{array}$ & $\begin{array}{c}\text { Reynolds } \\
\text { Number (1/ft) }\end{array}$ & $\begin{array}{c}\text { AOA } \\
(\mathbf{d e g})\end{array}$ \\
\hline 1 & 243,000 & 24,116 & $2.4350 \mathrm{e}-6$ & 391 & 24.87 & 63189 & 40.17 \\
\hline 6 & 200,767 & 18,164 & $1.6293 \mathrm{e}-5$ & 429 & 17.88 & 294950 & 39.02 \\
\hline
\end{tabular}

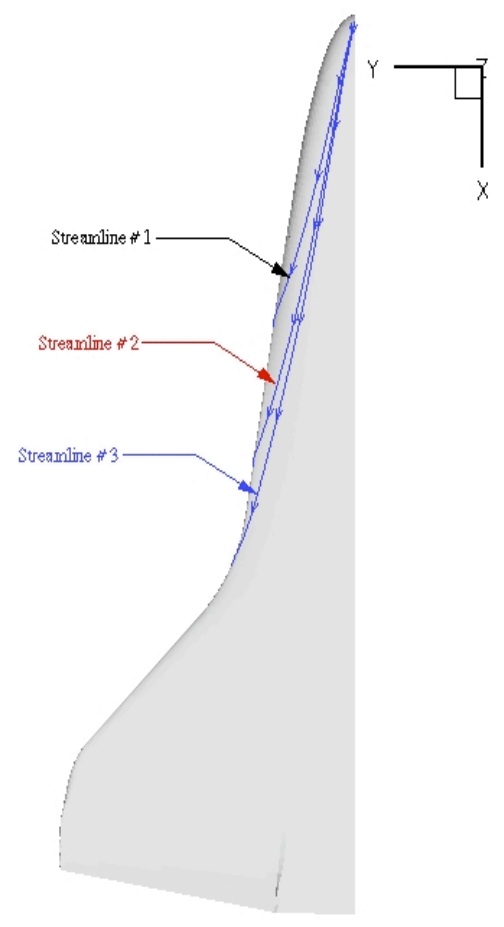

a) Case 1 - streamlines.

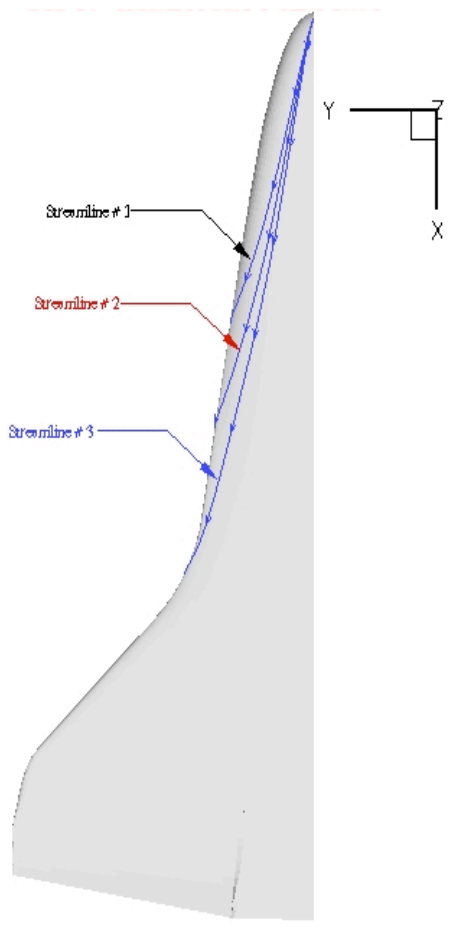

b) Case 6 - streamlines.

Figure 2.- STS-107 trajectory CFD along streamlines. 


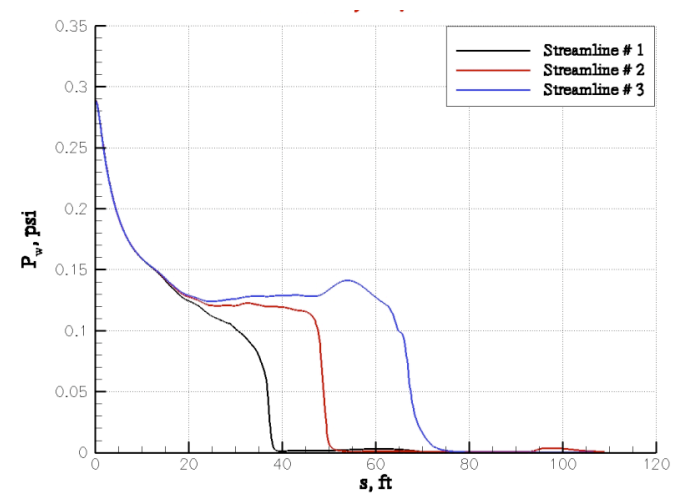

c) Case 1 - pressure.

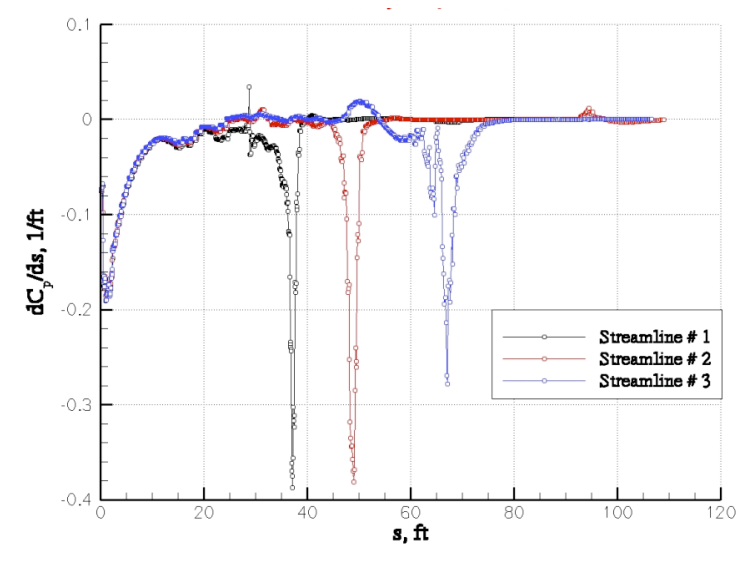

e) Case 1 - pressure gradient.

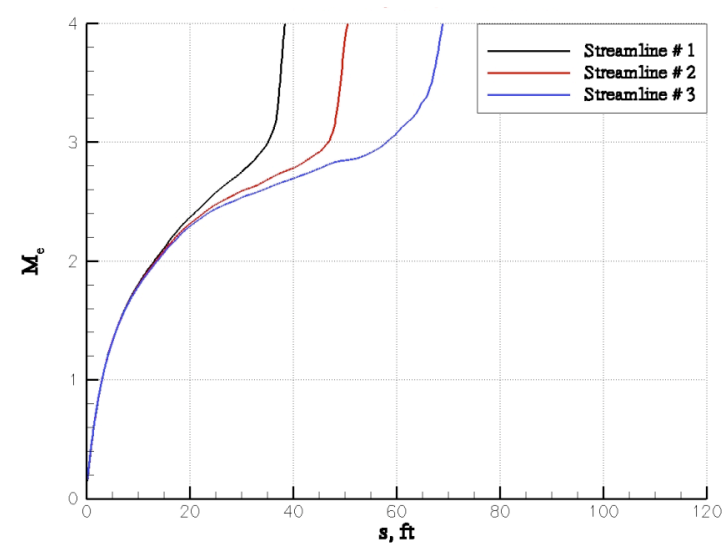

h) Case 1 - $M_{e}$.

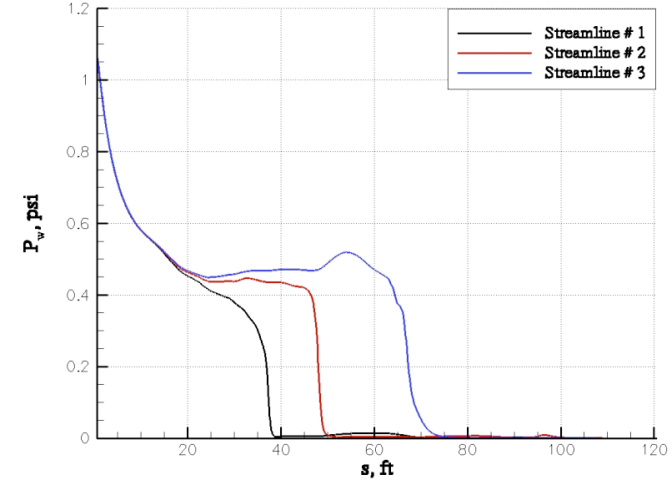

d) Case 6 - pressure.

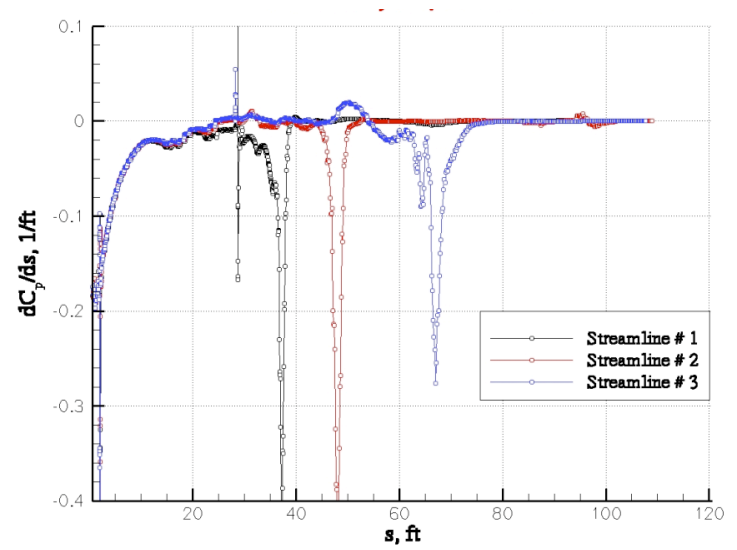

f) Case 6 - pressure gradient.

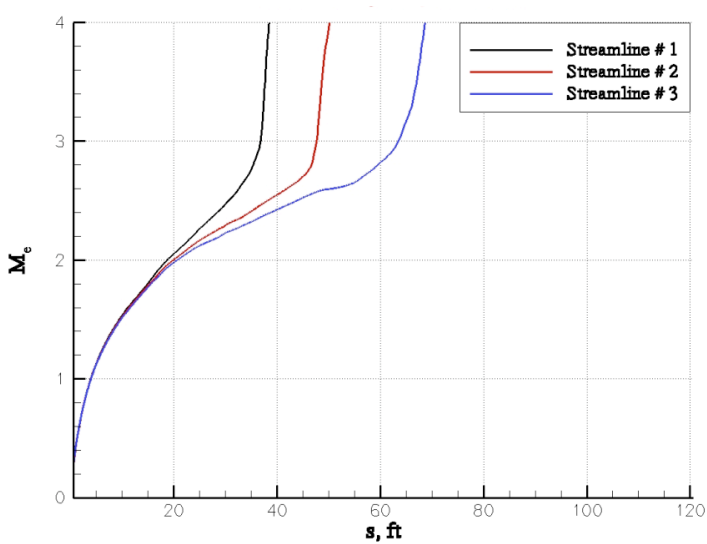

i) Case 6 - $M_{e}$.

Figure 2.-Continued. 


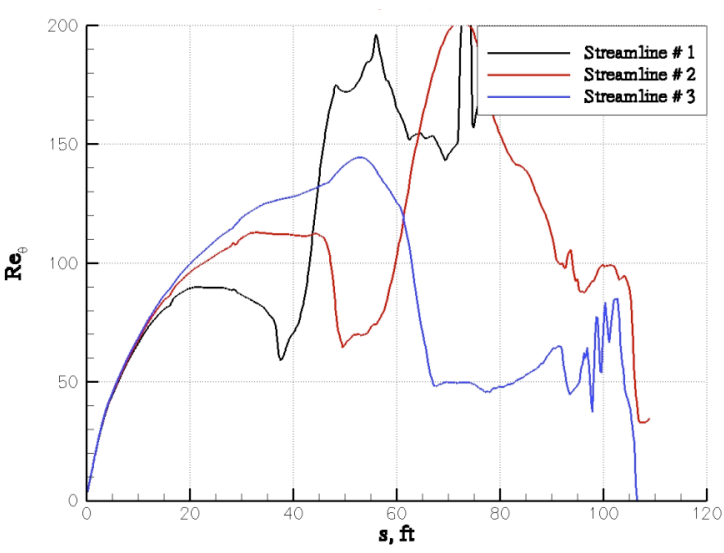

j) Case 1 - $\operatorname{Re}_{\theta}$.

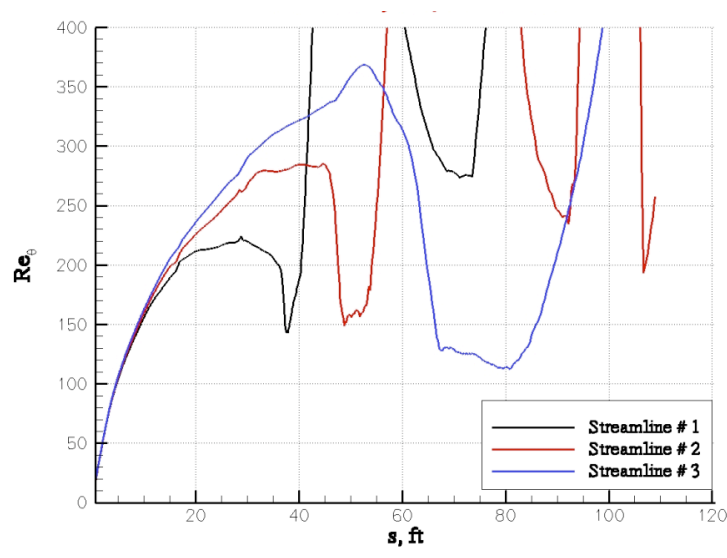

k) Case 6 - $\operatorname{Re}_{\theta}$.

Figure 2.-Concluded.

Given the infinity of potential geometric variations for impact damage, the Shuttle aeroheating community has defined a simplified cavity representation. This rectangular geometry (called the "shoebox" geometry due to its shape) consists of a flat bottom bounded by straight sides and end walls. Entry (upstream) and exit (downstream) and side wall angles are prescribed for the general case. However, for the sake of simplicity, vertical sides and ends are used for the present designs. According to existing literature, the governing parameters for a cavity are the length-to-depth ratio $(\mathrm{L} / \mathrm{H})$, and the depth-to-boundary-layer-thickness ratio $(\mathrm{H} / \delta)$. Lack of detailed width-effect information in the literature leads to the decision to scale the width by the depth $(\mathrm{W} / \mathrm{H})$. Two different cavity lengths were selected, both legacy lengths from previous testing. The first is a short cavity of length $\mathrm{L} / \mathrm{H}=7.2$ that is representative of an open cavity; and, the second is a long cavity of length $\mathrm{L} / \mathrm{H}=20$, representative of a closed cavity. Prior testing experience and published information in the literature indicate that the heating is more pronounced in closed, deep cavities that allow a significant expansion of the flow into the cavity, particularly when there is impingement on the floor. Accordingly, to match existing, unpublished data, a target cavity depth of $\mathrm{H} / \delta=1.1$ is selected. Additionally, a larger $\mathrm{H} / \delta$ translates (via L/H) into a longer cavity, L, enabling better optical access for the measurement system. Also, even though this may be deeper than most damage sites on the Shuttle in flight, such a cavity would produce a stronger heating signal that is required to appropriately address the effect of the pressure gradient, and to develop an accurate assessment of the associated uncertainties. For both cavities, width is selected as $\mathrm{W} / \mathrm{H}=3.6$ to enhance the optical access needed for the global phosphor thermography used in this study.

\section{Experiment Design}

This section outlines the experiment design process. First, the design philosophy is presented, along with physical constraints imposed on the process. This is followed by the development of the model test-surface geometries using two-dimensional CFD simulations, then a full three-dimensional CFD assessment that is used as a consistency check is presented. In the final section, the cavity design is generated, yielding the corresponding, available test space for these models.

\section{A. Design Philosophy and Constraints}

Two different nearly-constant pressure gradient test surfaces were developed to isolate the influence of pressure gradient on cavity heating augmentation. The first used a flat-surface geometry where $\mathrm{dC}_{\mathrm{p}} / \mathrm{ds} \approx 0.0$, allowing consistency with existing data; the other provided a gradient near the target value of $\mathrm{dC}_{\mathrm{p}} / \mathrm{ds} \approx-0.15 / \mathrm{ft}(-0.013 / \mathrm{inch})$. As these surfaces were being developed, the variation of the surface flow properties were mapped as a function of model test conditions and attitude (i.e. $\mathrm{Pt}_{1}, \mathrm{Tt}_{1}, \alpha, \mathrm{M}_{\mathrm{e}}$, and $\mathrm{Re}_{\theta}$ ). Next, the cavity test location on the plate, $\mathrm{X}_{\text {cav }}$, was established downstream of the rapidly varying pressure gradients that occur as flow expands over the leading edge. This location was selected so that the desired scaled cavity with prescribed $(\mathrm{H} / \delta, \mathrm{W} / \mathrm{H}, \mathrm{L} / \mathrm{H})$ yielded reasonable dimensions in geometric space $(\mathrm{H}, \mathrm{W}, \mathrm{L})$ for measurement resolution. Because of the uniqueness of each model surface, there is only a single test point 


$$
\left(\mathrm{M}_{\mathrm{e}}, \mathrm{Re}_{\theta}, \mathrm{H} / \delta, \mathrm{W} / \mathrm{H}, \mathrm{L} / \mathrm{H}\right)_{\text {Flat Surface Cavity }}=\left(\mathrm{M}_{\mathrm{e}}, \mathrm{Re}_{\theta}, \mathrm{H} / \delta, \mathrm{W} / \mathrm{H}, \mathrm{L} / \mathrm{H}\right)_{\text {Gradient Surface Cavity }}
$$

where the cavity entry conditions were matched. Also, it is important to note that the available test domain for each model was developed naturally as a part of the design process.

Other design constraints were considered in addition to matching cavity entry conditions. First, a blunted nose model was required to reduce the edge Mach numbers to target values at smaller angles of attack, thus minimizing the possibility of partial or complete tunnel-flow blockage (Dye, Everhart, and Hodge 1992). Effect of nose radius (Rn) was assessed as a part of the baseline flat plate design process. Second, the model width was made large enough to remove possible interference of side-edge vortices on the model test region and to minimize spanwise flow-gradient effects across the model. According to Micol (1995), the 31-Inch Mach 10 Tunnel test core is safely 10 inches at the smallest freestream Reynolds number. Therefore, a model width of 10 inches was selected. Finally, with proper mounting, models as long as 30 inches can be injected through the tunnel sidewall. However, there are low-pressure limitations on flow expansion for negative pressure gradient models that further limit the length of the model (the pressure can not be reduced below zero). Model length was defined during the design as nominally 20 inches.

\section{B. Two-Dimensional Surface Modeling}

Two-dimensional (2D) viscous modeling of the test surfaces was performed using the LAURA computational fluid dynamics code (Gnoffo, et al., 1989, 1990). Solutions for the flat surface were computed for leading edge nose radius values $(\mathrm{Rn})$ of $0.0625,0.1250$, and 0.1875 inches for a range of stream conditions covering tunnel $\mathrm{Re}_{\infty}=0.5$ $\times 10^{6}, 1.0 \times 10^{6}, 1.8 \times 10^{6}$, and $2.0 \times 10^{6}$ at anticipated model angles of attack, $\alpha$, ranging from -25 to 10 degrees. Most of the expected initial large change in the pressure was completed by the 5-inch station for all conditions, particularly for the expanding flow conditions that occur around the test surface for positive angles of attack, though some slight gradient effects remain as the boundary layer continued to grow on the plate. The smallest nose radius was not selected because of fabrication concerns. Overall, relatively small differences were observed when comparing the effects of the 0.1250 -inch nose radius to the 0.1875 -inch nose radius on the boundary layer edge conditions. For consistency with other experiments, the 0.1250-inch nose was selected. Sample surface flow computations for the flat surface are present in Fig. 3.
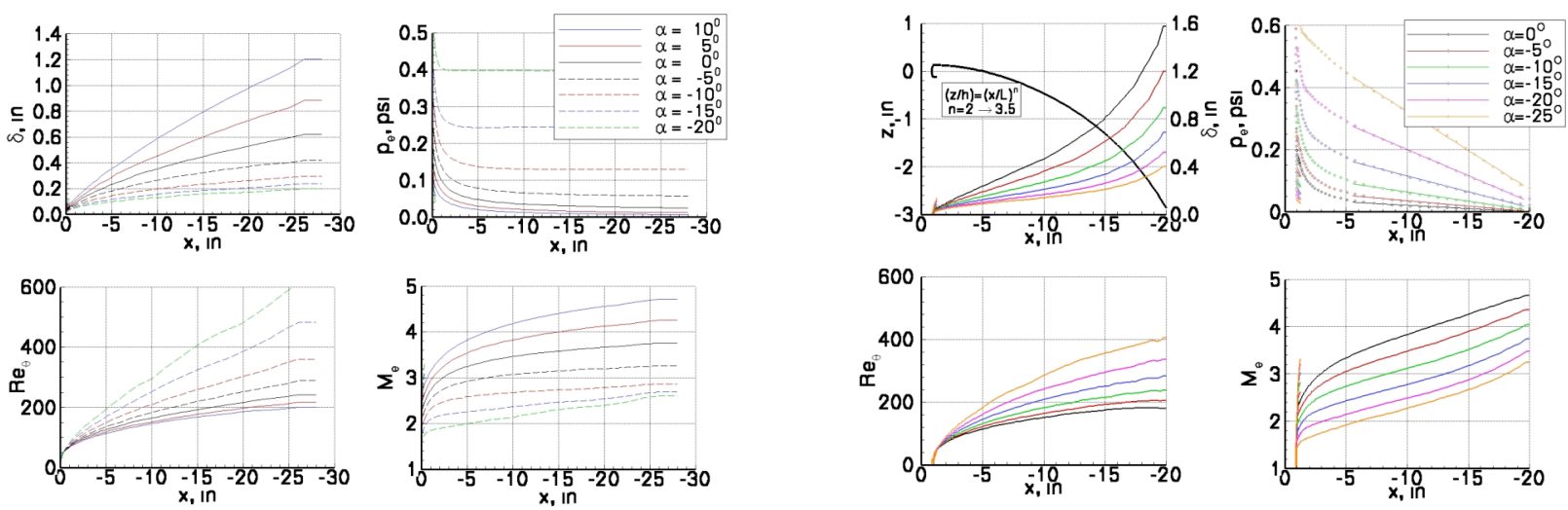

Figure 3.- Flat plate surface flow properties for $\operatorname{Re}_{\infty}=1 \times 10^{6}$.

Figure 4.- Expansion plate surface flow properties for $\operatorname{Re}_{\infty}=1 \times 10^{6}$.

The challenge of designing an expansion surface was to maintain a linear longitudinal pressure distribution along the extent of the model, yielding a constant gradient, $\mathrm{dC}_{\mathrm{p}} / \mathrm{dx}$ of the required magnitude over the cavity test region. Initially, power law surfaces of the form $\left(\mathrm{z} / \mathrm{z}_{\mathrm{ref}}\right)=\left(\mathrm{x} / \mathrm{L}_{\mathrm{ref}}\right)^{\mathrm{n}}$ were assumed with constant $\mathrm{n}$ values. However, the pressure gradient over these surfaces was not constant, though the surface did yield a nearly constant Mach number gradient. Subsequently, a reasonably constant pressure gradient was obtained by allowing $\mathrm{n}$ to vary parabolically along the surface according to $n=2.0+1.5\left(\mathrm{x} / \mathrm{L}_{\mathrm{ref}}\right)^{2}$. Values of 3 inches and 26.55 inches were used for $\mathrm{z}_{\mathrm{ref}}$ and $\mathrm{L}_{\text {ref }}$, respectively. Sample computational results for the final geometry are presented in Figure 4. Solid colored lines are 
used to represent the numerical solutions for different angles of attack with the exception of those on the pressure versus $\mathrm{x}$ subplot, where a consistent line-color-matched set of symbols is used. The solid lines through the symbols on the pressure versus $\mathrm{x}$ subplot represent a linear least squares fit from $x=6$ to $x=19$ inches. As can be observed, very satisfactory results for the linearity are achieved.

The pressure gradient plotted versus angle of attack is present in Figure 5 for both the flat and expansion surfaces. Notably, for the expansion model the gradient is insensitive to the stream Reynolds number; but is highly dependent on the angle of attack. For the flat model, the gradient variation is very small with respect to $\alpha$ and is insensitive to $\operatorname{Re}$ (as with the expansion model). Prescribing a specific value of $\mathrm{dC}_{\mathrm{p}} / \mathrm{dx}$ at a given set of cavity entry conditions (i.e. $\mathrm{M}_{\mathrm{e}}$ and $\mathrm{Re}_{\theta}$ ) ties the results to a specific location on the vehicle surface, which goes beyond the binary yes/no question being addressed here. To achieve such a set of conditions would require additional iterations of the test surface geometry.

\section{Three-Dimensional Flow Assessment}

The center of the plates are expected to be predominantly $2 \mathrm{D}$ flow in the streamwise direction, but three-dimensional (3D) flow relief is known to exist near the plate edges and the spanwise extent of this non-uniformity must be established. Ideally, instrumented pressure models would be tested to directly measure the baseline pressure gradients to check the validity of the two-dimensional design assumptions; however, resource limitations prevented this approach. An alternative approach was to perform a fully three-dimensional numerical assessment using the LAURA CFD code.

To perform the $3 \mathrm{D}$ analysis, the support strut, which connects the leeward surface of the test article to the wind tunnel, was not modeled, but the expansionsurface plate and the mounting plate between the test article and the strut were retained. This produces a curved surface similar to a super-critical airfoil shape, shown in Figure 6. Additionally illustrated is the O-O grid topology used to map a 4.5 million point, 120 block decomposition on the plate to accommodate

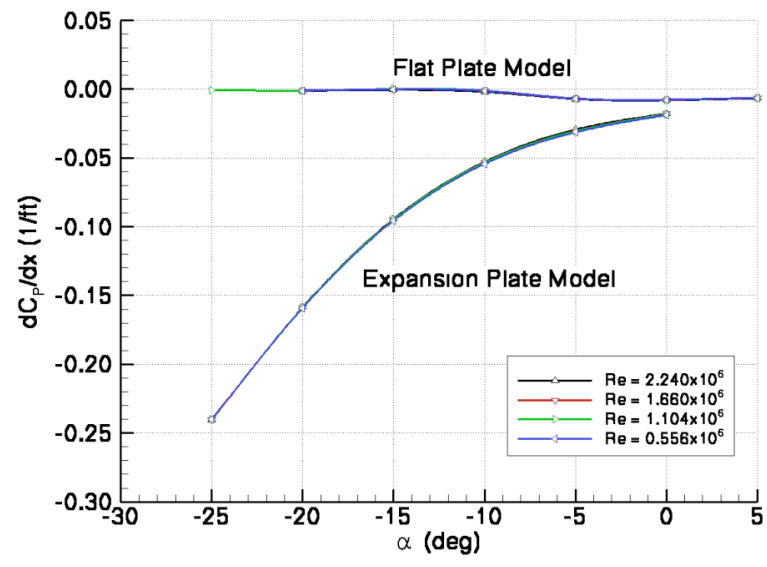

Figure 5.- Pressure gradient variation with $\alpha$ for flat and expansion models.

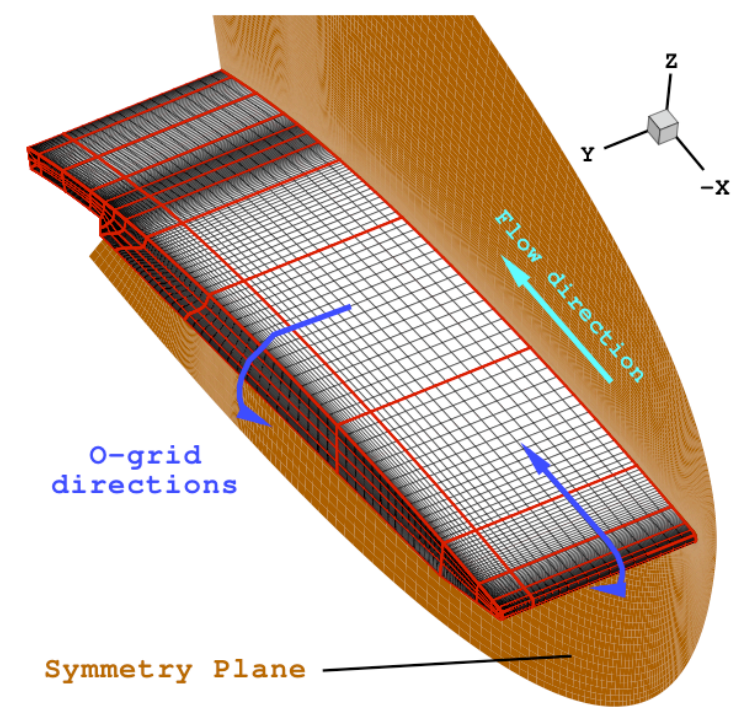

Figure 6.- Surface grid topology used to model the constant pressure-gradient expansion plate. gradients around the corners of the plate and provide adequate resolution of the flow in high gradient regions. The structured grid was dimensioned to provide the necessary doubling in grid dimensionality to enable grid convergence studies required for the assessment of solution accuracy. Three grid resolutions were used, termed coarse, medium, and fine, where each was eight times as large as the previously smaller mesh. Grid convergence for this study was obtained when the heat transfer, or heating, at the windside surface did not change by more than 5\% in the region of interest. Solution convergence was obtained when the $\mathrm{L}_{2}$ norm of the residuals was at least 6 orders of magnitude less than where the solution started and the change in heating was less than $1 \%$ between 2000 iterations with sufficiently large relaxation rates for both viscous and inviscid terms. Utilizing these conditions, the grid-converged state of the centerline pressure distributions were compared to the 2D flow analyses in Figure 7. 


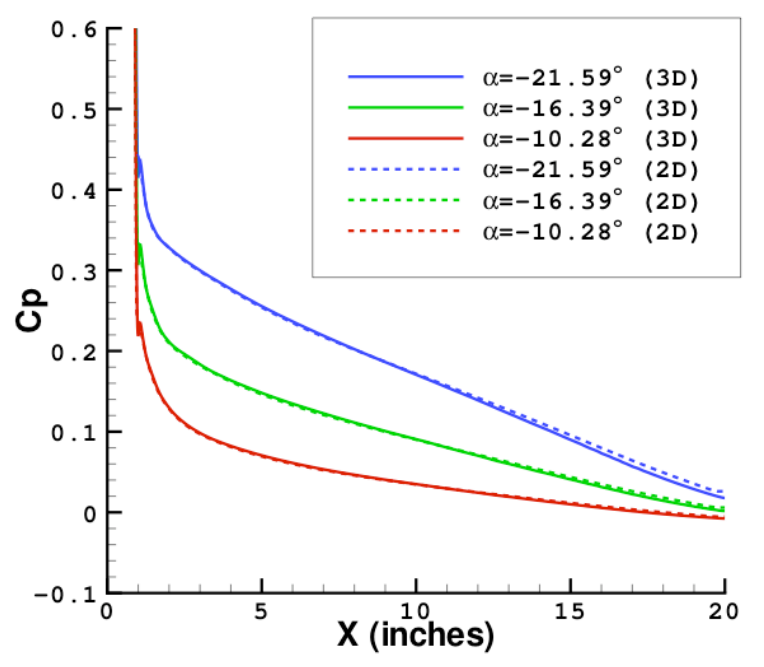

Figure 7.- Two-and three-dimensional pressure coefficient along the centerline of the expansion plate.

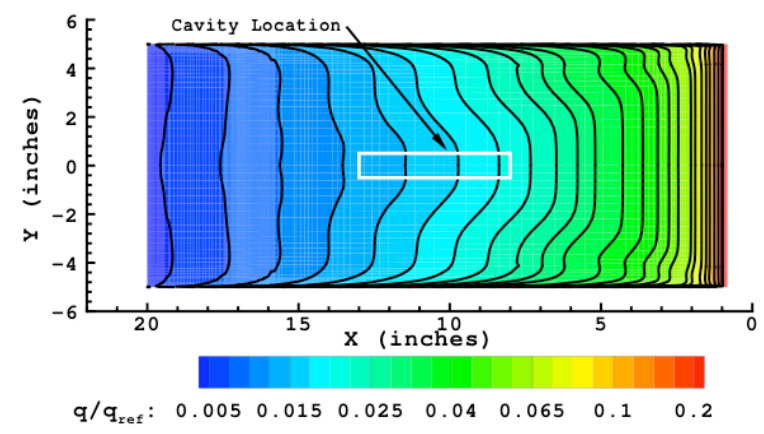

Figure 8.- Surface heat transfer coefficient for $\alpha=16^{\circ}$ and $\operatorname{Re}_{\infty}=1.3 \times 10^{6} / \mathrm{ft}$.

For design of the plate, the 2D and 3D flow simulations are in good agreement, each yielding a nearly constant pressure gradient along the streamwise direction of the flow. Referring to the surface heat transfer coefficient distributions in Figure 8, the cavities will be located in the white box region on the plate centerline. (Note that the longitudinal axis is reversed in this figure because of a coordinate system difference in the CFD formulation, yielding the leading edge at $\mathrm{x}=20$ inches and the trailing edge at approximately $x=1$ inch.) According to the constant heating contours, 2D effects are maintained a minimum of half an inch from the centerline with some expected spanwise 3D degradation beyond. Complete geometry computations with and without a centerline symmetry condition were evaluated and indicated no significant change from the half plate solutions used for the present example. Therefore, use of the plate for $2 \mathrm{D}$ flow experimental work should pose no issue with respect to the flow field and streamwise pressure gradient.

\section{Test Condition Selection and Cavity Design}

Next, the location of the leading edge of the cavities needed to be determined along with the final cavity dimensions. The 8-inch station was selected as the cavity leading edge position based on the following factors: 1) the constant pressure gradient location begins at approximately 5 inches (see Figs. 3 and 4), 2) thicker boundary layers allow larger cavities, 3) the target-condition requirement for the magnitude and range of $\mathrm{Re}_{\theta}$, and 4) the downstream narrowing of the plate side-edge vortices. Test conditions at this location were interpolated from the CFD surface flow distributions, and they are presented in terms of performance charts for the flat and expansion surfaces in Fig. 9 and Fig. 10, respectively. In these figures, $M_{e}, R_{\theta}, \delta$, and $\theta$ are plotted versus $P_{T 1}$ for various angles of attack. The effect of $\mathrm{T}_{\mathrm{T} 1}$ for the range of conditions considered was second order; therefore, it was neglected when determining the boundary layer edge properties. For each test surface, three nominal edge Mach number conditions $(2.25,2.50$, and 2.85) covering the target range were specified. At each edge Mach number condition, the available $\mathrm{Re}_{\theta}$ space was determined from the curves, along with the $\alpha$ required to achieve these entry conditions; then, the corresponding $\delta$ and $\theta$ were determined to help scale the cavities. Because flow develops differently over an expansion plate from that developing over flat plate, the tunnel conditions and $\alpha$ were unique to each model. Likewise the actual geometric size of each cavity was unique, because the value of $\delta$ at $\mathrm{x}=8$ was different for each model at the prescribed entry conditions. The boundary layer edge conditions were re-evaluated using the actual test conditions, and these conditions were used for data reduction and post-test analysis.

Surface flow conditions derived from the performance charts suggested that target edge conditions of $\mathrm{M}_{\mathrm{e}}=2.5$ and $\mathrm{Re}_{\theta}=220$ could be readily achieved on both the model surfaces and that a centered range of off-design conditions would be available. The resulting boundary layer thickness at this condition was used as the scaling factor for the cavity depth, $\mathrm{H} / \delta$. The as-built cavity dimensions are presented in Table 2 . The original intent was to develop baseline models to acquire heating, pressure, and oil flow information to characterize the undisturbed 
environment and a measured pressure gradient; however, only the baseline heating model was built and tested due to resource limitations.
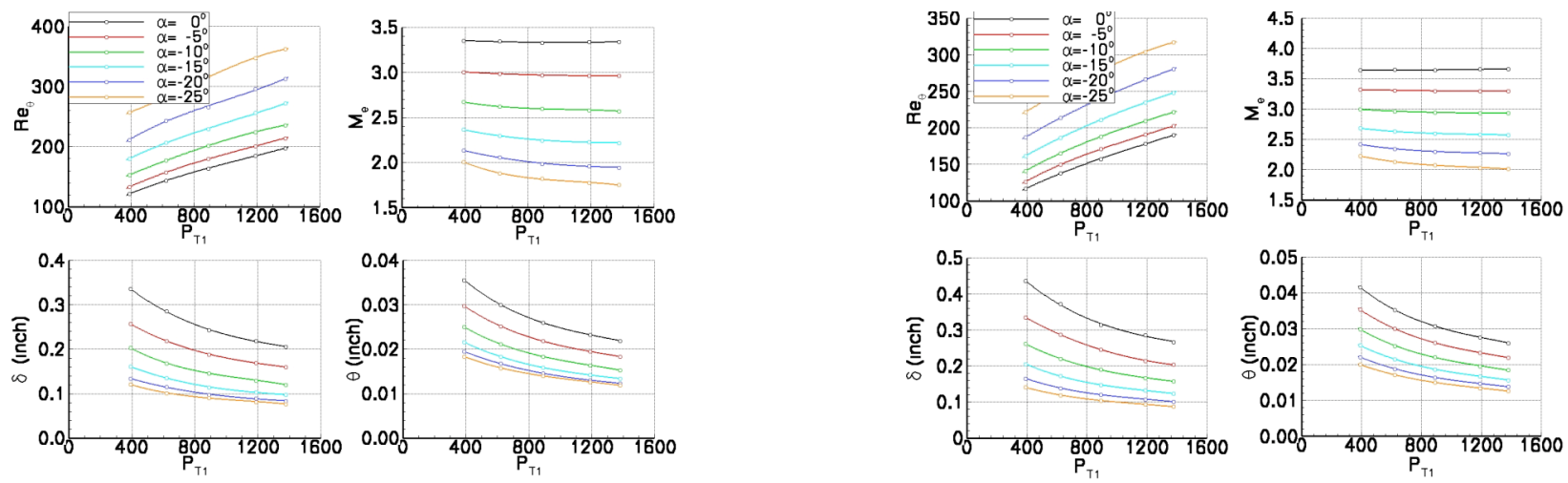

Figure 9.- Flat plate performance chart.
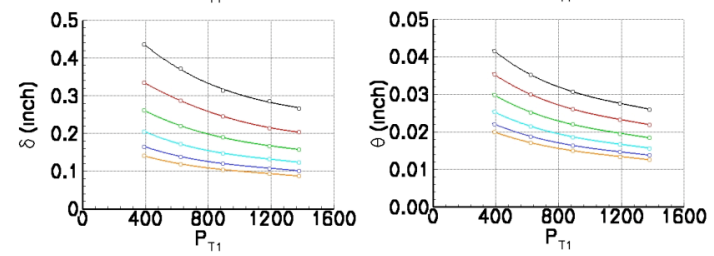

Figure 10.- Expansion model performance chart.

Table 2.- As-built cavity geometries.

\begin{tabular}{|cccccc|}
\hline Model & $\begin{array}{c}\text { H } \\
\text { (inch) }\end{array}$ & $\begin{array}{c}\text { W } \\
\text { (inch) }\end{array}$ & L (inch) & W/H & L/H \\
\hline \multicolumn{7}{c|}{ CLOSED - Long Cavity } \\
Expansion & 0.1443 & 0.5268 & 2.9011 & 3.65 & 20.1 \\
Flat & 0.2095 & 0.7474 & 4.1622 & 3.57 & 19.9 \\
\hline \multicolumn{7}{c}{ OPEN - Short Cavity } \\
Expansion & 0.1462 & 0.5218 & 1.0445 & 3.57 & 7.1 \\
Flat & 0.2095 & 0.7496 & 1.4969 & 3.58 & 7.1 \\
\hline
\end{tabular}

\section{Experimental Method}

The experimental methods are presented here, beginning with a description of the test facility and nominal tunnel flow conditions. This is followed by a description of the model fabrication process, a discussion of the phosphor coating used for making the heating measurements, and the model mounting. An overview of the phosphor data system used to acquire the global heating measurements is next presented, followed by the post-test data mapping and scaling. The test data are presented in tabular form, first as a summary of the cavity and run parameters for each model, and then as global images of the surface heating. Finally, an uncertainty analysis is developed and sample results are presented in the form of global images of the bias and total uncertainty.

\section{A. Facility}

The 31-Inch Mach 10 Air Tunnel was selected as the test facility because the higher surface temperature rise during a run would provide lower uncertainties in heat transfer measurements (Merski 2001). This is a blowdown facility in which heated, filtered air is used as the test gas. The tunnel has a square, contoured nozzle, which opens into a 31-inch square test section. Models are supported on a hydraulically operated, sidewall-mounted injection system that can transfer a model from the sealed model box to the tunnel center-line in less than 0.6 seconds. Tunnel run times of approximately 60 seconds can be achieved, but typical heating studies require only a few seconds. The nominal reservoir conditions are stagnation pressures of $150 \mathrm{psi}$ to $1450 \mathrm{psi}$ at stagnation temperatures of about $1825^{\circ} \mathrm{R}$. These reservoir conditions very nearly produce perfect gas $(\gamma=1.4)$ freestream flows with a Mach number of approximately 10 and Reynolds numbers of $0.2 \times 10^{6} / \mathrm{ft}$ to $2.2 \times 10^{6} / \mathrm{ft}$. Nominal flow conditions are provided in Table 3 and a detailed description of this facility is presented by Micol (1995). 
Table 3.- Nominal flow conditions for the 31-Inch Mach 10 Air Tunnel.

\begin{tabular}{|cccccccccc|}
\hline $\begin{array}{c}\mathbf{P}_{\mathbf{T 1}} \\
\mathbf{p s i}\end{array}$ & $\begin{array}{c}\mathbf{T}_{\mathbf{T 1}} \\
{ }^{\circ} \mathbf{R}\end{array}$ & $\begin{array}{c}\mathbf{P}_{\infty} \mathbf{x 1 0} \mathbf{1}^{\mathbf{2}} \\
\mathbf{p s i}\end{array}$ & $\begin{array}{c}\mathbf{T}_{\infty} \\
{ }^{\circ} \mathbf{R}\end{array}$ & $\begin{array}{c}\mathbf{q}_{\infty} \\
\mathbf{p s i}\end{array}$ & $\begin{array}{c}\mathbf{V}_{\infty} \\
\mathbf{f t} / \mathbf{s}\end{array}$ & $\mathbf{M}_{\infty}$ & $\begin{array}{c}\mathbf{R}_{\infty} \mathbf{x 1 0}^{-\mathbf{6}} \\
\mathbf{f t}^{-1}\end{array}$ & $\begin{array}{c}\mathbf{P}_{\mathbf{t}, 2} \\
\mathbf{p s i}\end{array}$ & $\begin{array}{c}\text { Test Core } \\
\text { in. }\end{array}$ \\
\hline 348 & 1800 & 0.992 & 95.2 & 0.650 & 4628 & 9.67 & 0.568 & 1.205 & $10 \times 10$ \\
723 & 1825 & 1.867 & 94.2 & 1.259 & 4670 & 9.81 & 1.104 & 2.334 & $12 \times 12$ \\
1452 & 1800 & 3.509 & 90.7 & 2.430 & 4643 & 9.94 & 2.240 & 4.503 & $12 \times 12$ \\
\hline
\end{tabular}

\section{B. Models}

The flat plate and expansion plate models used in this experiment were nominally 10 -inches wide by 20 -inches long. All models have a 0.125 -inch radius nose with a 15-degree wedge on the lower surface. The general manufacturing process for ceramic test articles is described in Buck, et al. (1993). Specific changes to this process for a previous, unpublished cavity heating experiment are described in Buck, et al. (2006). In this later manufacturing method, a rapid prototyping stereolithography (SLA) system at NASA Langley Research Center was used to make a resin mold pattern for casting cavities in flat 4-inch wide by 18 inch long ceramic insert models. These inserts were then installed in a 10 -inch wide by 28 -inch long steel flat-plate model for testing. The present experiment further improves this manufacturing process by eliminating the insert requirement. Here, the entire 10inch wide by 20 -inch long ceramic upper surface is cast as a single surface, including the nose, and it is then bonded to an aluminum backing plate. This improvement removes the step and gap mounting problems experienced during installation for testing with the previous method. The backing plate is at $0^{0}$

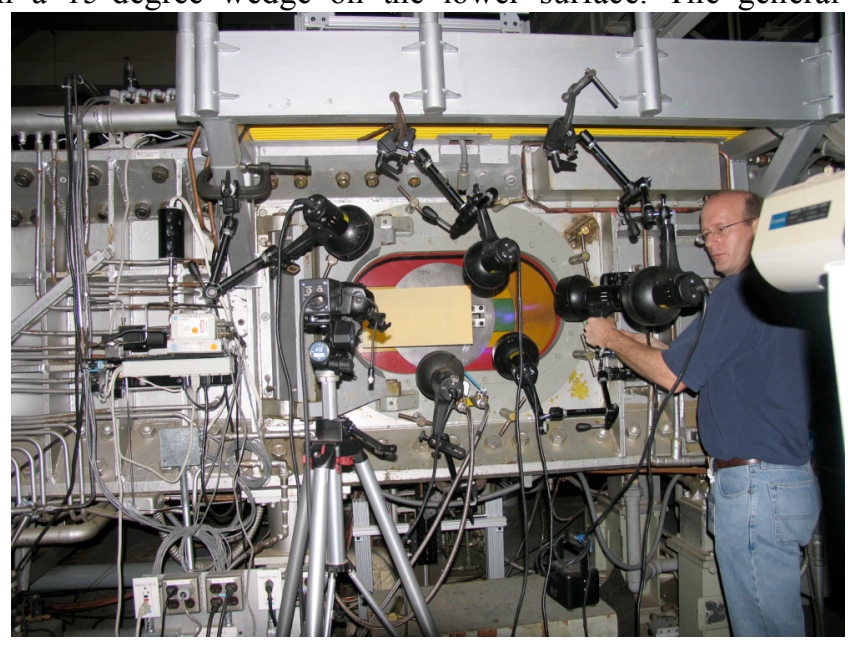

Figure 11.- Test model installed in 31-Inch Mach 10 Air Tunnel with TGP lighting and camera system. incidence relative to tunnel centerline for the flat plate, and it is offset at $8^{0}$ nose-up incidence for the expansion model. The cavities were machined into the plates, yielding sharp, well-defined edges and surfaces. These models were then coated with a mixture of phosphors suspended in a silica-based colloidal binder and sent to quality assurance for measurement and application of small circular locating markers, known as fiducial marks. These fiducial marks aid in data reduction and model orientation, and they can be seen in the run images as dark dots. Even though fiducial marks do not influence the flow over the model surface, they will influence the local heating measurement because the ink used in the process changes the calibration of the phosphor coating at their application point. Their influence on the data, notably in line cuts passing through them, is to produce a very short, very sharppeaked sinusoidal signature covering the diameter of the marking. When mounted in the tunnel, the aluminum backing plate was attached to a wedge block surface $\left(0^{0}\right.$ for the flat plate model and $8^{0}$ for the expansion model $)$ used to align the model to zero incidence. Finally, this entire assembly was attached from the leeward side to an existing model support strut and mounted to the tunnel sidewall injection plate. An offset angle wedge is placed under the strut base when required to extend the angle testing range of the model. A picture of the model mounted in the 31-Inch Mach 10 Tunnel with the phosphor thermography camera and lighting system is given in Fig. 11.

\section{Thermographic Phosphor Measurement System}

Global surface heating distributions were calculated using the two-color, relative-intensity, phosphorthermography aeroheating measurement method (Merski 1999). This is the standard method for obtaining aeroheating data in NASA Langley's hypersonic wind tunnels, and it can be used to identify the surface heating effects of complex three-dimensional flow phenomena, which are difficult to examine using conventional discretesensor methods. With this method, ceramic wind tunnel models are coated with phosphor crystals that fluoresce in the red and green regions of the visible light spectrum when illuminated by ultraviolet (UV) light. During a wind tunnel run, the phosphor-coated model is exposed to the heated flow of the tunnel, and the resulting changes in fluorescence intensity of the model are recorded and digitized through a 640 by 480 resolution color CCD (charge coupled device) camera and a state-of-the-art video acquisition system. The fluorescence intensity is dependent on 
both the intensity of the incident UV light and the local model surface temperature. The UV dependence is removed by taking the ratio of the green to red intensity images, from which surface temperature distributions are determined through prior calibrations. Images are acquired before the wind tunnel run and after injection of the model to the tunnel centerline during a run.

\section{Data Reduction}

Global mappings of the surface temperature obtained with the thermographic phosphor (TGP) data acquisition system were reduced to surface heating distributions using the IHEAT data reduction software (Merski 1999). In this method, phosphor images are acquired shortly after injection of the model to the tunnel centerline, which typically requires less than one second. With this software, temperature mappings acquired through the run are used to obtain heat transfer mappings. This is done by applying one-dimensional, semi-infinite-solid heat conduction theory assuming a constant heat-transfer coefficient, and by making empirical corrections to account for temperature changes in model substrate thermal properties. The results are presented in terms of a non-dimensional heat transfer coefficient ratio, $\mathrm{h} / \mathrm{h}_{\text {ref }}$, where $\mathrm{h}_{\text {ref }}$ is generally taken as $\mathrm{h}_{\mathrm{FR}}$, the theoretical heating computed with the Fay-Riddell (1958) theory. For this experiment, $\mathrm{h}_{\mathrm{FR}}$ was computed using a 0.125 -inch radius sphere (the test model nose radius) and a reference stagnation temperature of $540^{\circ} \mathrm{R}$. At this point, IHEAT was used to extract preliminary analysis data along lines from the two-dimensional heating images. Also, these images were mapped onto a three-dimensional representation of the test article using IHEAT's MAP3D photogrammetry program for further global analysis.

Data for this experiment were translated such that the leading edge of the cavity is at $\mathrm{x}=0$. The $(\mathrm{x}, \mathrm{y}, \mathrm{z})$ data were then scaled to $(\mathrm{x} / \mathrm{H}, \mathrm{y} / \mathrm{H}, \mathrm{z} / \delta)$ using the measured cavity depth, $\mathrm{H}$, and the computed boundary layer thickness, $\delta$. This yields a scaled-geometry cavity of depth $(\mathrm{H} / \delta)$, width $(\mathrm{W} / \mathrm{H})$, and length $(\mathrm{L} / \mathrm{H})$. Note again that the boundary layer edge conditions are determined from the LAURA computations for matching tunnel and model conditions for each run. For the contoured expansion models where $\mathrm{z}$ is not zero, a baseline longitudinal profile outside of the cavity is subtracted from the contour containing a cavity, yielding an incremental data surface where $z=0$ everywhere except in the cavity.

The impact of the cavity on the local undisturbed environment was assessed by converting the local heating data to heating augmentation or bump factor (BF) format by normalizing $\left(\mathrm{h}_{\text {local }} / \mathrm{h}_{\text {ref }}\right)$ by a reference-location average heating $\left(\mathrm{h}_{\mathrm{avg}} / \mathrm{h}_{\mathrm{ref}}\right)$, yielding $\mathrm{BF}=\left(\mathrm{h}_{\text {local }} / \mathrm{h}_{\mathrm{avg}}\right)$. In this format, $\mathrm{BF}=1$ is the nominal undisturbed condition for a flat plate; however, in an expanding flow BF will decrease slightly down the plate as the heating drops. For analysis consistency, $\left(\mathrm{h}_{\mathrm{avg}} / \mathrm{h}_{\mathrm{ref}}\right)$ is computed upstream of the cavity over an area two cavity depths long by one cavity width wide, and this region is located at $(-3 \leq \mathrm{x} / \mathrm{H} \leq-1)$ by $(-0.5 \mathrm{~W} / \mathrm{H} \leq \mathrm{y} / \mathrm{H} \leq 0.5 \mathrm{~W} / \mathrm{H})$.

\section{E. Presentation of Test Data}

For completeness, the as-run test conditions for the as-built cavity geometries are presented in Table 4 through Table 7. Each table represents the block of runs dedicated to a single configuration, providing the computed cavity entry conditions $\mathrm{M}_{\mathrm{e}}, \mathrm{Re}_{\theta}, \mathrm{Re}_{\theta} / \mathrm{M}_{\mathrm{e}}, \delta$, and $\theta$, as well as the cavity depth, width, and length normalized by the boundary layer thickness. The pressure gradient, $\mathrm{dC}_{\mathrm{p}} / \mathrm{dx}$, is also provided. Each configuration contains a randomly selected repeat run as a consistency check on the data acquisition and reduction processes. The corresponding mapped and scaled bump factor images are presented in Table 8 through Table 11 with the corresponding run number identified on each image. Following the usual convention, flow is from left to right. Note on some runs that the camera field of view truncates the image, introducing a cold arc-shaped region at the upstream top corner edge and a cold strip on the downstream edge spanning the model width. Examples of this truncation are visible in runs 23 through 25 and runs 55 through 66.

The images shown in Tables 8-11 provide a wealth of both local and global information, representing a significant analysis task unto itself, so only a few observational remarks are provided here. Flow entering the long, closed cavities (runs 23 through 44) is particularly noticeable in the augmented heating levels on the cavity floor. These cavities also exhibit enhanced vortical streaking and wiping that increases the local surface shearing, leading to large heating values on the cavity end wall and further downstream. In contrast and as expected, the short, open cavities (runs 45 through 66) are much cooler on the cavity floor. Large heating augmentation is only dominant on the downstream end wall lip. Though vortical streaking is still visible aft of the cavity, it decays rapidly. All of these observations are in accordance with published literature. Particularly noteworthy observations are that the location of peak heating may occur in the corners; depending on the flow conditions, peak heating will move laterally; and, discrete sensors placed on the centerline would in all likelihood have missed the peak heating values that are readily observed when using TGP methods. 
Table 4.- Expansion Plate Model - $\mathrm{L} / \mathrm{H}=20, \mathrm{~W} / \mathrm{H}=3.6$ Cavity.

\begin{tabular}{|cc|cc|rcccccc|}
\hline Run & Model & \multicolumn{1}{c}{$\mathbf{M}_{\mathbf{e}}$} & $\mathbf{R e}_{\boldsymbol{\theta}}$ & $\mathbf{R e}_{\boldsymbol{\theta}} / \mathbf{M}_{\mathbf{e}}$ & $\boldsymbol{\delta}$ (inch) & $\boldsymbol{\theta}$ (inch) & $\begin{array}{c}\mathbf{d C}_{\mathbf{p}} / \mathbf{d x} \\
(\mathbf{1} / \mathbf{f t})\end{array}$ & $\mathbf{H} / \boldsymbol{\delta}$ & $\mathbf{W} / \boldsymbol{\delta}$ & $\mathbf{L} / \boldsymbol{\delta}$ \\
\hline 23 & Exp & 2.848 & 151 & 53 & 0.2340 & 0.0275 & -0.071 & 0.62 & 2.3 & 12.4 \\
24 & Exp & 2.872 & 171 & 60 & 0.2070 & 0.0242 & -0.063 & 0.70 & 2.5 & 14.0 \\
26 & Exp & 2.897 & 211 & 73 & 0.1653 & 0.0193 & -0.055 & 0.87 & 3.2 & 17.6 \\
27 & Exp & 2.910 & 190 & 65 & 0.1844 & 0.0217 & -0.057 & 0.78 & 2.9 & 15.7 \\
28 & Exp & 2.377 & 196 & 82 & 0.1606 & 0.0211 & -0.159 & 0.90 & 3.3 & 18.1 \\
29 & Exp & 2.441 & 213 & 87 & 0.1402 & 0.0186 & -0.131 & 1.03 & 3.8 & 20.7 \\
30 & Exp & 2.487 & 234 & 94 & 0.1283 & 0.0166 & -0.110 & 1.12 & 4.1 & 22.6 \\
31 & Exp & 2.499 & 254 & 102 & 0.1173 & 0.0152 & -0.110 & 1.23 & 4.5 & 24.7 \\
32 & Exp & 2.309 & 214 & 93 & 0.1409 & 0.0194 & -0.183 & 1.02 & 3.7 & 20.6 \\
33 & Exp & 2.353 & 234 & 100 & 0.1245 & 0.0167 & -0.144 & 1.16 & 4.2 & 23.3 \\
34 & Exp & 2.414 & 254 & 105 & 0.1154 & 0.0152 & -0.124 & 1.25 & 4.6 & 25.1 \\
\hline
\end{tabular}

Table 5.- Flat Plate Model $-\mathrm{L} / \mathrm{H}=20, \mathrm{~W} / \mathrm{H}=3.6$ Cavity.

\begin{tabular}{|cc|rc|rrrrrrr|}
\hline Run & Model & \multicolumn{1}{|c|}{$\mathbf{M}_{\mathbf{e}}$} & $\mathbf{R e}_{\boldsymbol{\theta}}$ & $\mathbf{R e}_{\boldsymbol{\theta}} / \mathbf{M}_{\mathbf{e}}$ & $\boldsymbol{\delta}$ (inch) & $\boldsymbol{\theta}$ (inch) & $\begin{array}{c}\mathbf{d C}_{\mathbf{p}} / \mathbf{d x} \\
(\mathbf{1} / \mathbf{f t})\end{array}$ & $\mathbf{H} / \boldsymbol{\delta}$ & $\mathbf{W} / \boldsymbol{\delta}$ & $\mathbf{L} / \boldsymbol{\delta}$ \\
\hline 35 & Flat & 2.825 & 186 & 66 & 0.2166 & 0.0259 & -0.004 & 0.97 & 3.4 & 19.2 \\
36 & Flat & 2.847 & 204 & 72 & 0.1961 & 0.0234 & -0.004 & 1.07 & 3.8 & 21.2 \\
37 & Flat & 2.873 & 224 & 78 & 0.1811 & 0.0214 & -0.005 & 1.16 & 4.1 & 23.0 \\
38 & Flat & 2.900 & 244 & 84 & 0.1691 & 0.0197 & -0.005 & 1.24 & 4.4 & 24.6 \\
39 & Flat & 2.407 & 220 & 91 & 0.1634 & 0.0219 & 0.000 & 1.28 & 4.6 & 25.5 \\
40 & Flat & 2.461 & 241 & 98 & 0.1477 & 0.0194 & 0.000 & 1.42 & 5.1 & 28.2 \\
41 & Flat & 2.478 & 260 & 105 & 0.1347 & 0.0175 & 0.000 & 1.55 & 5.5 & 30.9 \\
42 & Flat & 2.170 & 278 & 128 & 0.1242 & 0.0178 & -0.001 & 1.69 & 6.0 & 33.5 \\
43 & Flat & 2.205 & 301 & 136 & 0.1107 & 0.0155 & 0.000 & 1.89 & 6.8 & 37.6 \\
44 & Flat & 2.461 & 241 & 98 & 0.1477 & 0.0194 & 0.000 & 1.42 & 5.1 & 28.2 \\
\hline
\end{tabular}

Table 6.- Expansion Plate Model - $\mathrm{L} / \mathrm{H}=7.2, \mathrm{~W} / \mathrm{H}=3.6$ Cavity.

\begin{tabular}{|cc|rr|rrrrrrr|}
\hline Run & Model & \multicolumn{1}{|c|}{$\mathbf{M}_{\mathbf{e}}$} & $\mathbf{R e}_{\boldsymbol{\theta}}$ & $\mathbf{R e}_{\boldsymbol{\theta}} / \mathbf{M}_{\mathbf{e}}$ & $\boldsymbol{\delta}$ (inch) & $\boldsymbol{\theta}$ (inch) & $\begin{array}{c}\mathbf{d C}_{\mathbf{p}} / \mathbf{d x} \\
(\mathbf{1} / \mathbf{f t})\end{array}$ & $\mathbf{H} / \boldsymbol{\delta}$ & $\mathbf{W} / \boldsymbol{\delta}$ & $\mathbf{L} / \boldsymbol{\delta}$ \\
\hline 55 & Exp & 2.848 & 151 & 53 & 0.2339 & 0.0437 & -0.071 & 0.62 & 2.2 & 4.5 \\
56 & Exp & 2.580 & 191 & 74 & 0.1648 & 0.0210 & -0.063 & 0.89 & 3.2 & 6.3 \\
57 & Exp & 2.910 & 190 & 65 & 0.1844 & 0.0217 & -0.057 & 0.79 & 2.8 & 5.7 \\
58 & Exp & 2.897 & 211 & 73 & 0.1653 & 0.0193 & -0.055 & 0.88 & 3.2 & 6.3 \\
59 & Exp & 2.377 & 196 & 82 & 0.1606 & 0.0211 & -0.159 & 0.91 & 3.2 & 6.5 \\
62 & Exp & 2.442 & 213 & 87 & 0.1406 & 0.0187 & -0.131 & 1.04 & 3.7 & 7.4 \\
63 & Exp & 2.487 & 233 & 94 & 0.1287 & 0.0167 & -0.110 & 1.14 & 4.1 & 8.1 \\
61 & Exp & 2.499 & 254 & 102 & 0.1173 & 0.0152 & -0.110 & 1.25 & 4.4 & 8.9 \\
64 & Exp & 2.309 & 214 & 93 & 0.1409 & 0.0194 & -0.183 & 1.04 & 3.7 & 7.4 \\
65 & Exp & 2.353 & 234 & 100 & 0.1245 & 0.0167 & -0.144 & 1.17 & 4.2 & 8.4 \\
66 & Exp & 2.414 & 254 & 105 & 0.1154 & 0.0152 & -0.124 & 1.27 & 4.5 & 9.1 \\
67 & Exp & 2.442 & 213 & 87 & 0.1406 & 0.0187 & -0.131 & 1.04 & 3.7 & 7.4 \\
\hline
\end{tabular}

Table 7.- Flat Plate Model - $\mathrm{L} / \mathrm{H}=7.2, \mathrm{~W} / \mathrm{H}=3.6$ Cavity.

\begin{tabular}{|cc|rr|rrrrrrr|}
\hline Run & Model & \multicolumn{1}{|l}{$\mathbf{M}_{\mathbf{e}}$} & $\mathbf{R e}_{\boldsymbol{\theta}}$ & $\mathbf{R e}_{\boldsymbol{\theta}} / \mathbf{M}_{\mathbf{e}}$ & $\boldsymbol{\delta}$ (inch) & $\boldsymbol{\theta}$ (inch) & $\begin{array}{c}\mathbf{d C}_{\mathbf{p}} / \mathbf{d x} \\
(\mathbf{1} / \mathbf{f t})\end{array}$ & $\mathbf{H} / \boldsymbol{\delta}$ & $\mathbf{W} / \boldsymbol{\delta}$ & $\mathbf{L} / \boldsymbol{\delta}$ \\
\hline 45 & Flat & 2.825 & 186 & 66 & 0.2167 & 0.0278 & -0.004 & 0.97 & 3.5 & 6.9 \\
46 & Flat & 2.847 & 204 & 72 & 0.1961 & 0.0234 & -0.004 & 1.07 & 3.8 & 7.6 \\
47 & Flat & 2.873 & 224 & 78 & 0.1810 & 0.0213 & -0.005 & 1.16 & 4.1 & 8.3 \\
48 & Flat & 2.900 & 244 & 84 & 0.1691 & 0.0197 & -0.005 & 1.24 & 4.4 & 8.9 \\
49 & Flat & 2.407 & 220 & 91 & 0.1633 & 0.0219 & 0.000 & 1.28 & 4.6 & 9.2 \\
50 & Flat & 2.461 & 241 & 98 & 0.1477 & 0.0194 & 0.000 & 1.42 & 5.1 & 10.1 \\
51 & Flat & 2.477 & 260 & 105 & 0.1347 & 0.0175 & 0.000 & 1.56 & 5.6 & 11.1 \\
52 & Flat & 2.170 & 278 & 128 & 0.1241 & 0.0178 & -0.001 & 1.69 & 6.0 & 12.1 \\
53 & Flat & 2.205 & 301 & 136 & 0.1107 & 0.0155 & 0.000 & 1.89 & 6.8 & 13.5 \\
54 & Flat & 2.825 & 186 & 66 & 0.2166 & 0.0259 & -0.004 & 0.97 & 3.5 & 6.9 \\
\hline
\end{tabular}


Table 8.- Expansion Plate Bump Factor Images $-\mathrm{L} / \mathrm{H}=\mathbf{2 0}, \mathrm{W} / \mathrm{H}=3.6$.

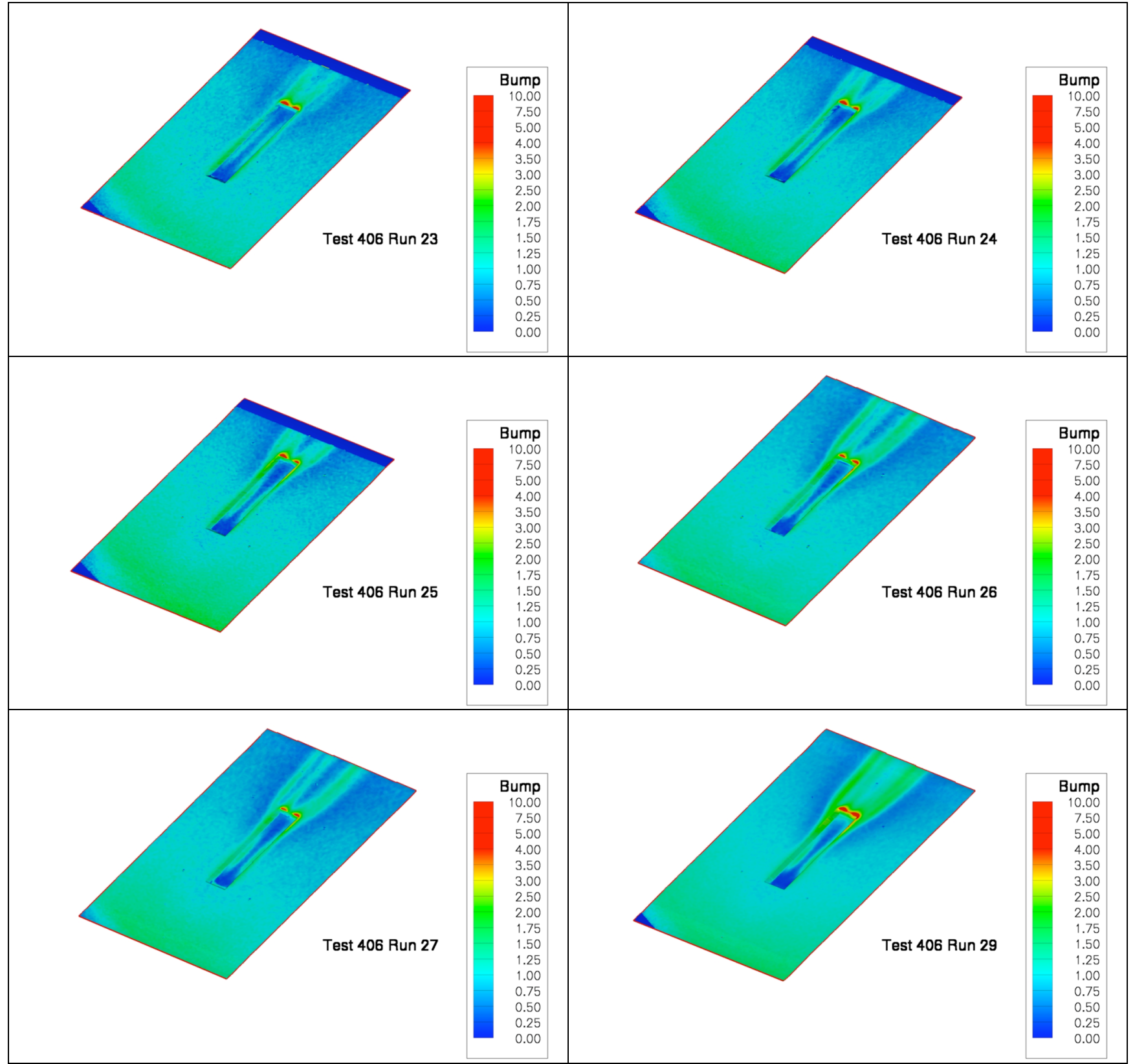


Table 8.- Concluded.

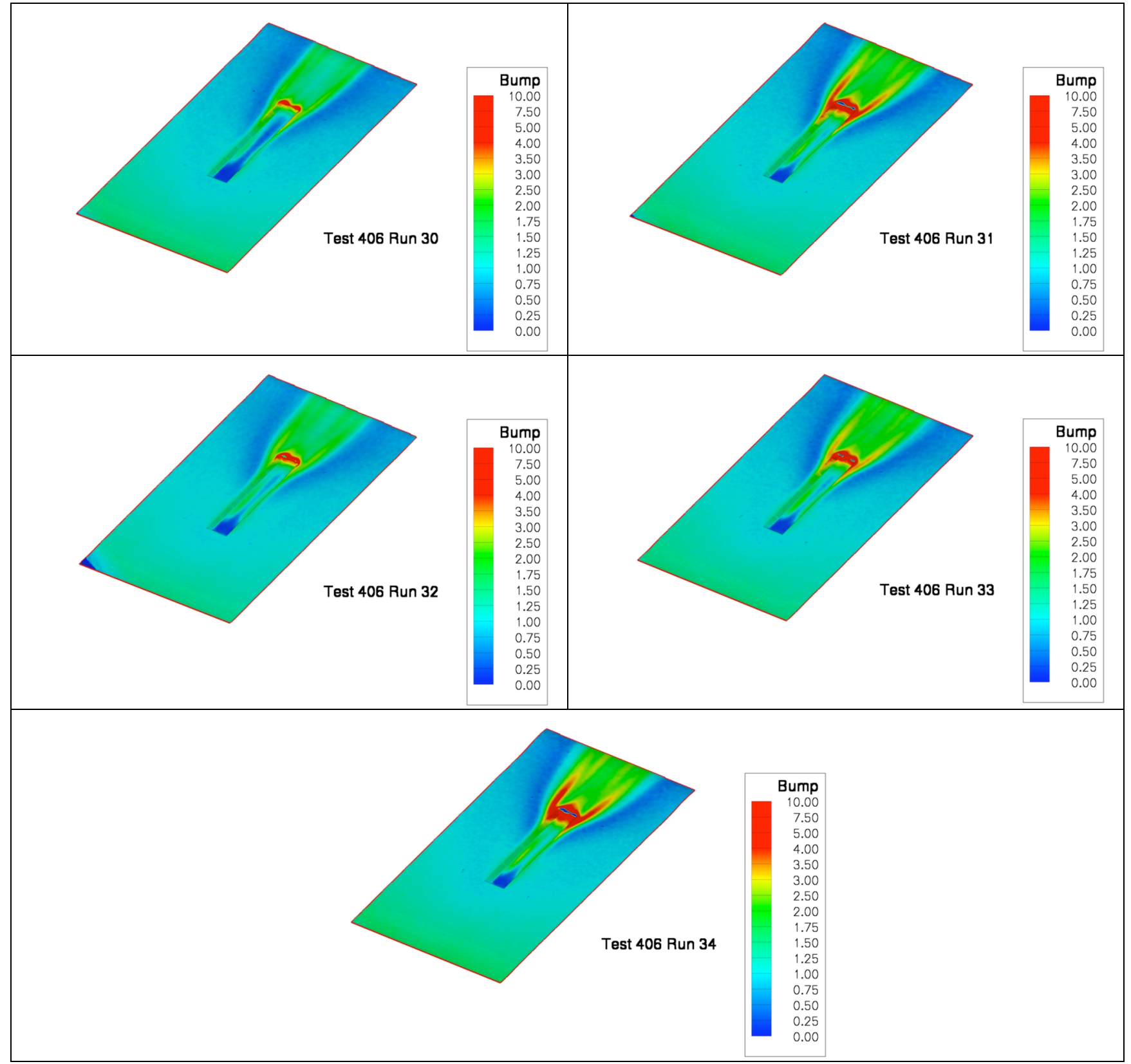


Table 9.- Flat Plate Bump Factor Images - $\mathrm{L} / \mathrm{H}=\mathbf{2 0}, \mathrm{W} / \mathrm{H}=3.6$.

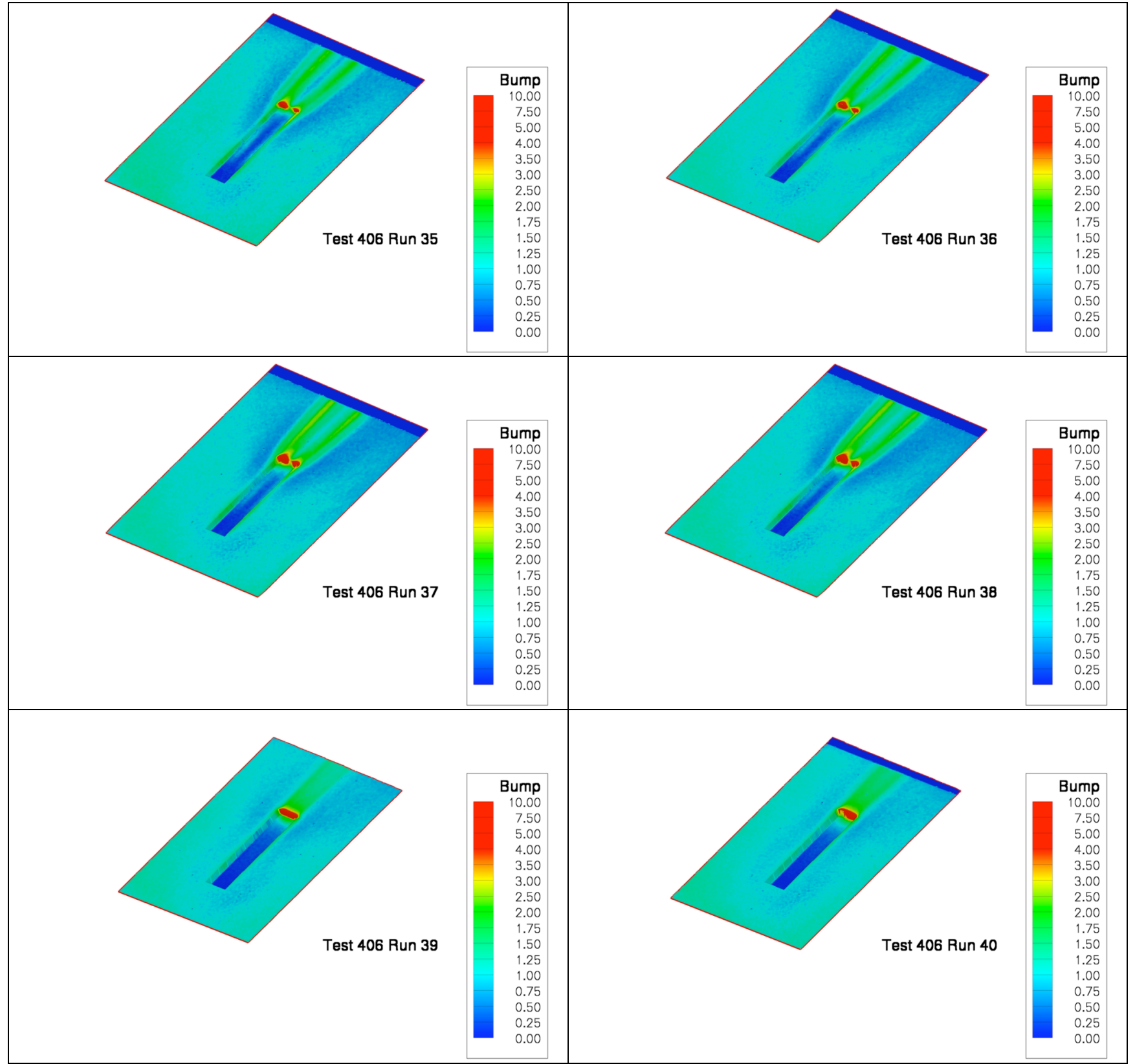


Table 9.- Concluded.

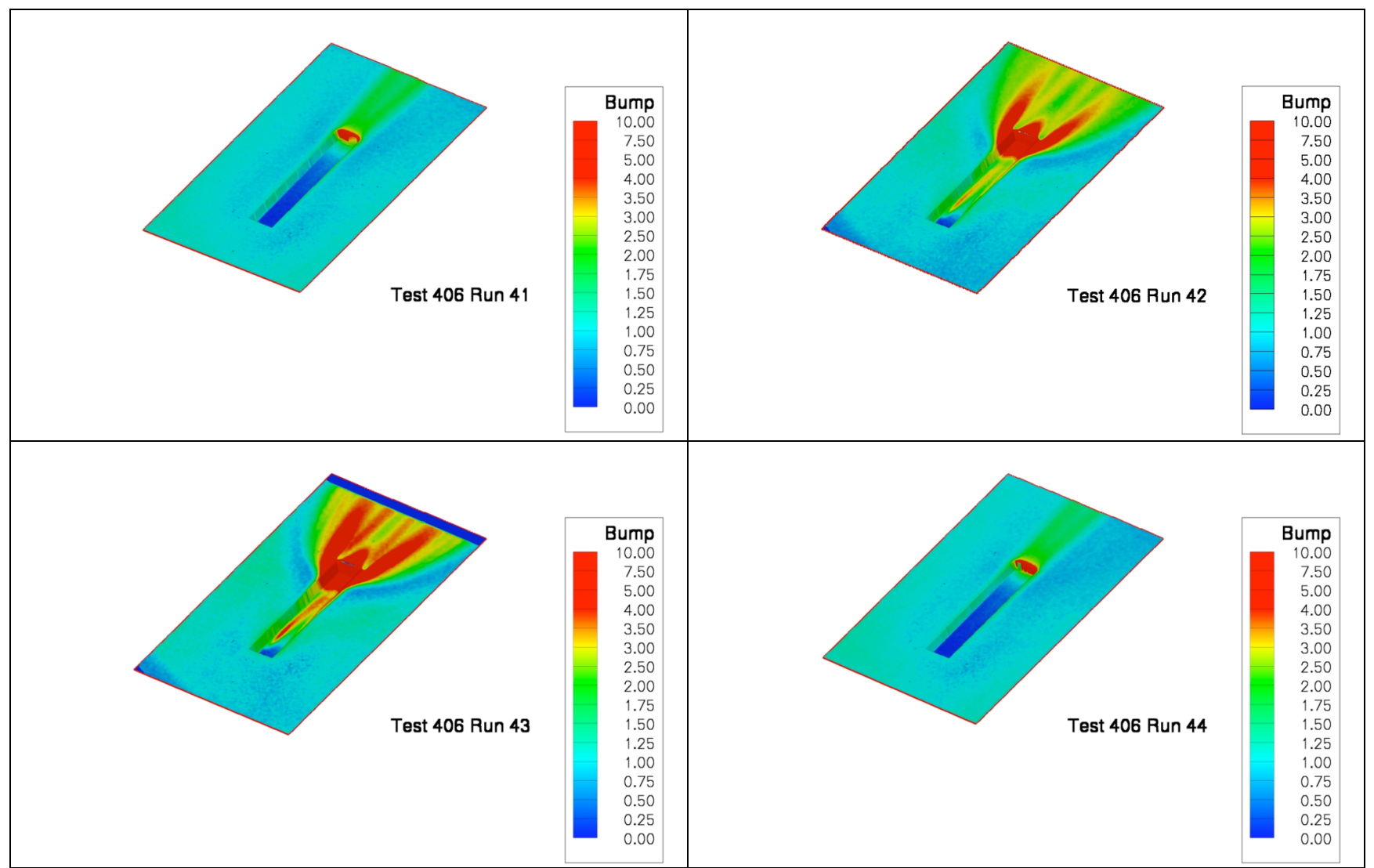

Table 10.- Expansion Plate Bump Factor Images $-\mathrm{L} / \mathrm{H}=7.2, \mathrm{~W} / \mathrm{H}=3.6$.

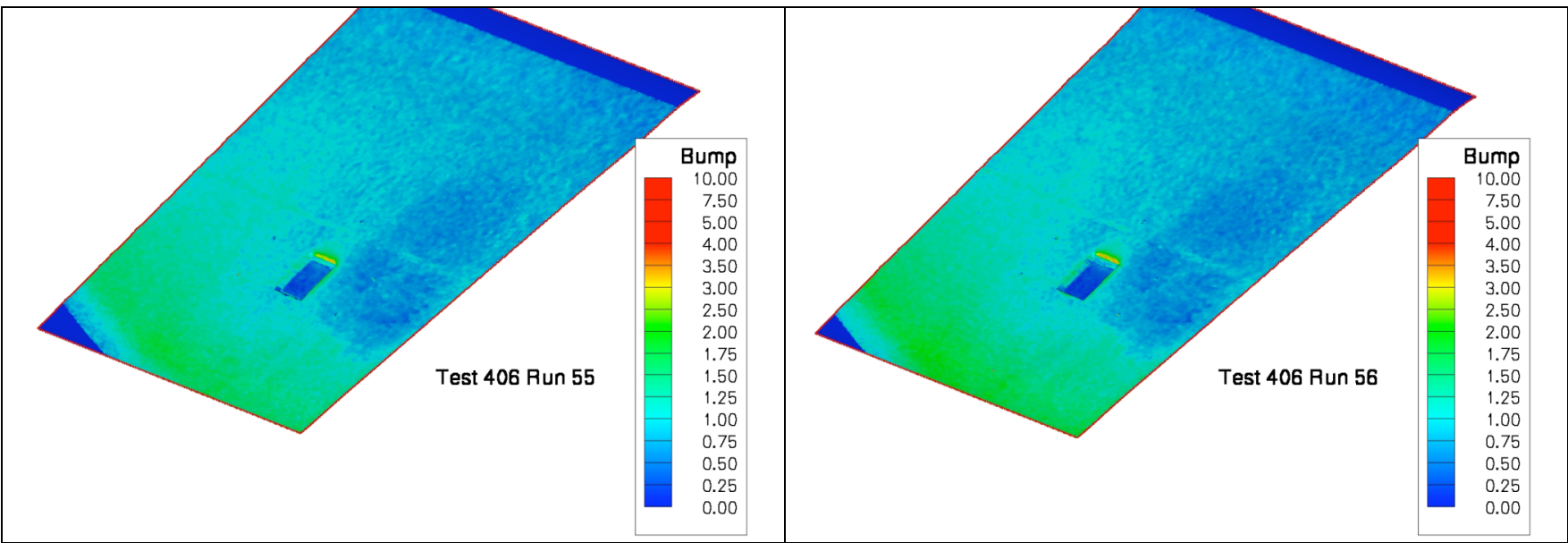


Table 10.- Continued.

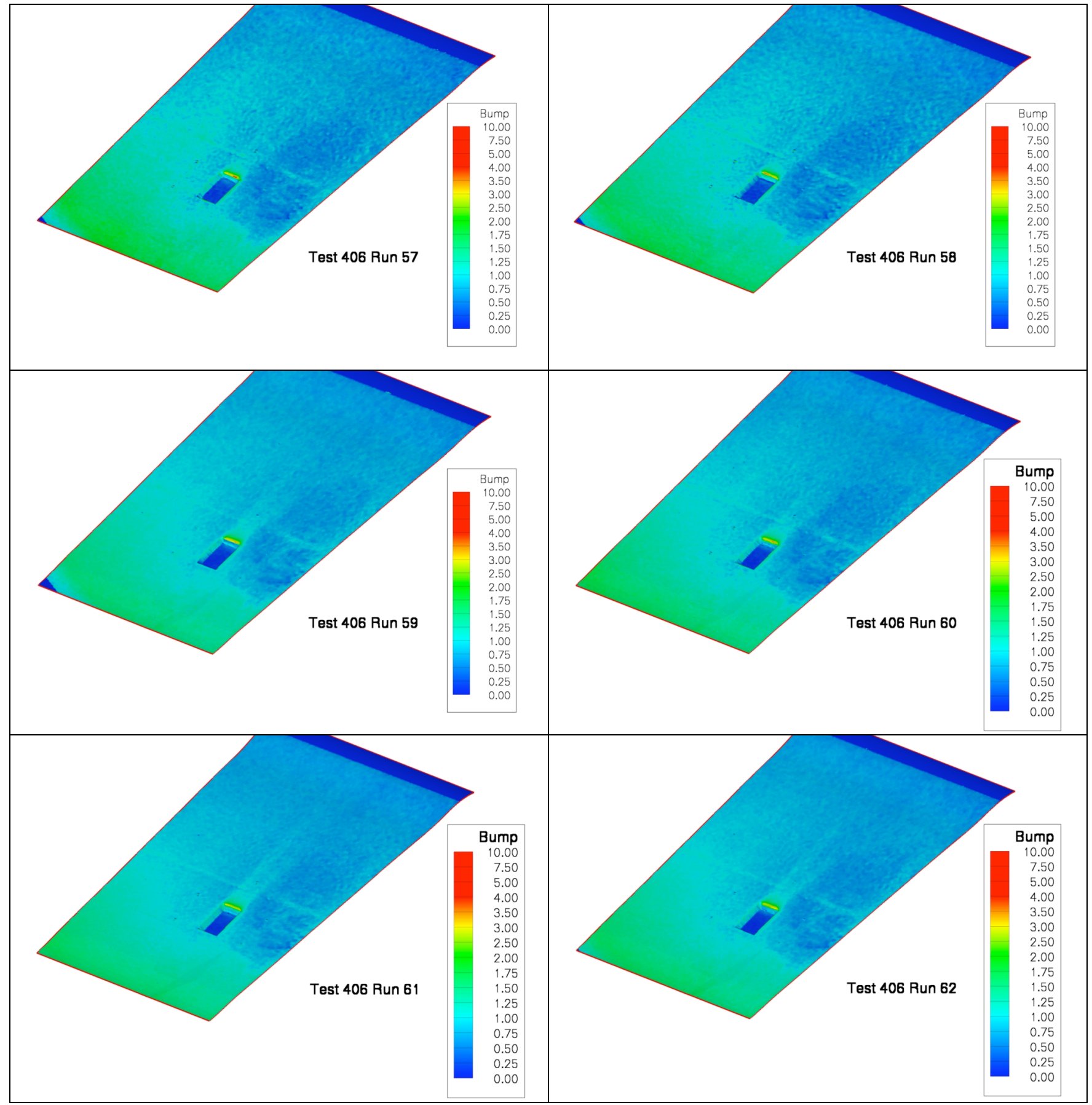


Table 10.- Concluded.

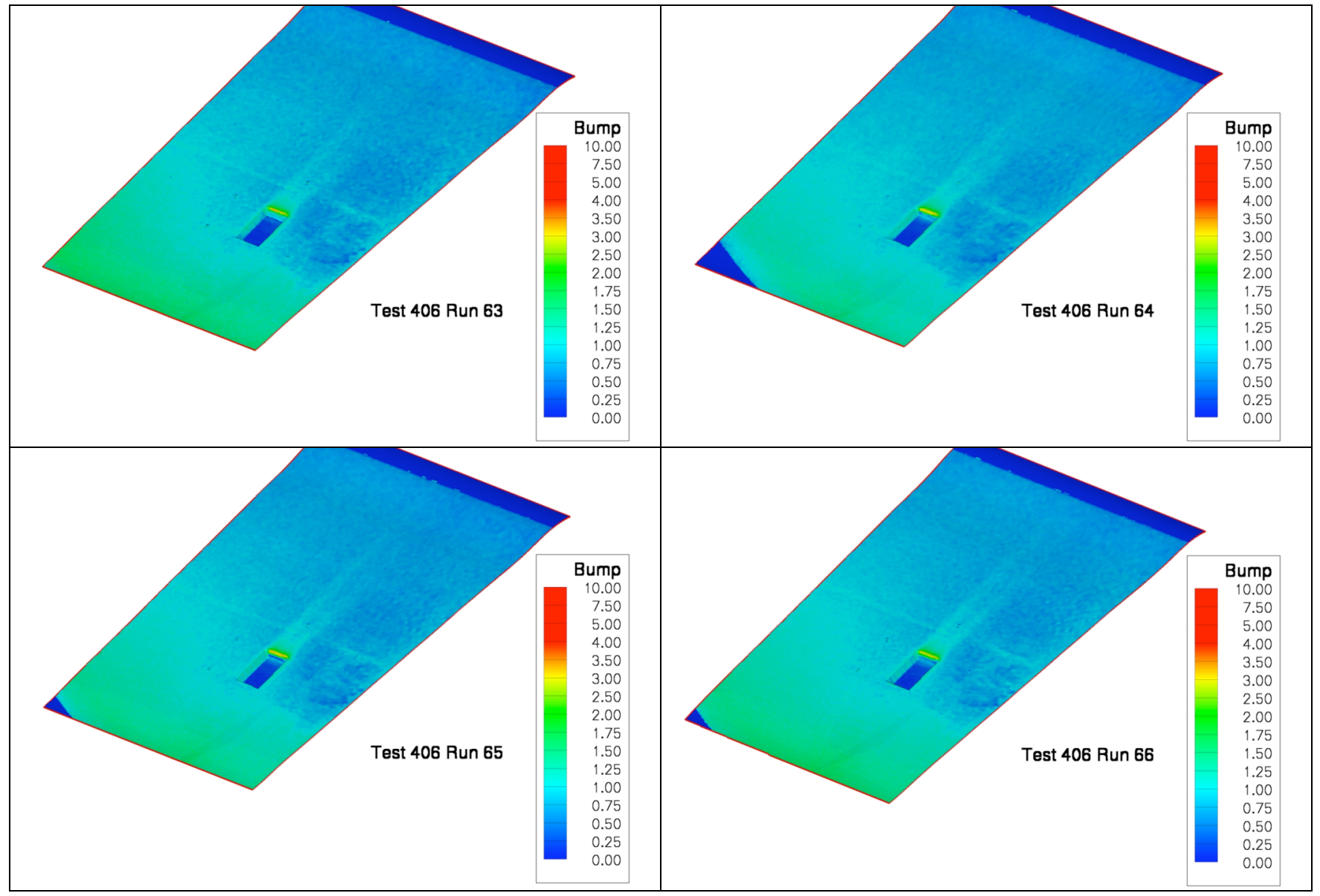

Table 11.- Flat Plate Bump Factor Images $-\mathrm{L} / \mathrm{H}=7.2, \mathrm{~W} / \mathrm{H}=3.6$.

\begin{tabular}{|c|c|c|c|}
\hline Test 406 Run 45 & $\begin{array}{r}\text { Bump } \\
10.00 \\
7.50 \\
5.00 \\
4.00 \\
3.50 \\
3.00 \\
2.50 \\
2.00 \\
1.75 \\
1.50 \\
1.25 \\
1.00 \\
0.75 \\
0.50 \\
0.25 \\
0.00\end{array}$ & Test 406 Run 46 & $\begin{array}{r}\text { Bump } \\
10.00 \\
7.50 \\
5.00 \\
4.00 \\
3.50 \\
3.00 \\
2.50 \\
2.00 \\
1.75 \\
1.50 \\
1.25 \\
1.00 \\
0.75 \\
0.50 \\
0.25 \\
0.00\end{array}$ \\
\hline
\end{tabular}


Table 11.- Concluded.

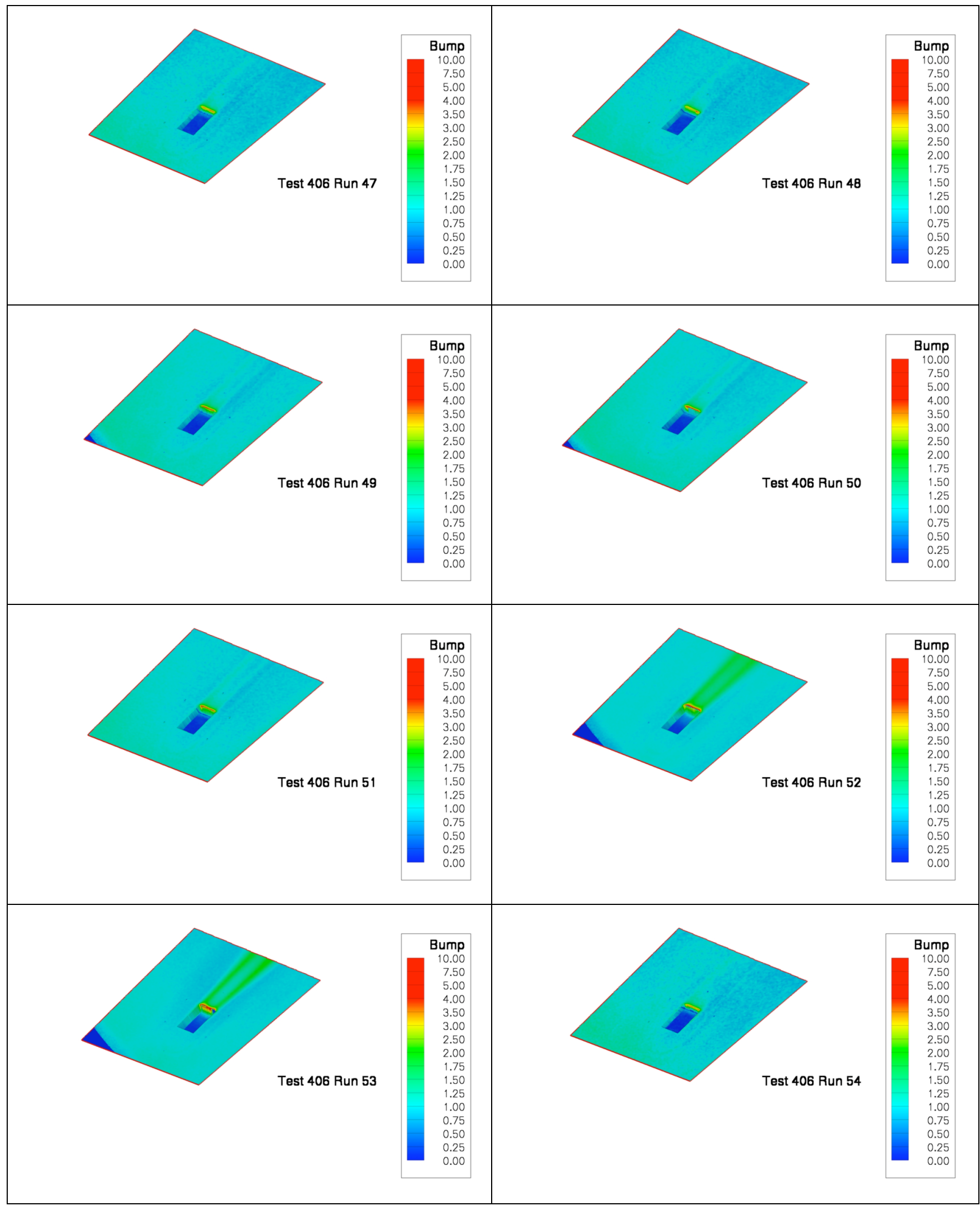

21 of 28

AIAA Paper 2006-0185 


\section{F. Uncertainty Analysis}

Merski published the uncertainties for the phosphor thermography method as a whole in 1999. A more quantitative understanding of the uncertainty levels for this experiment were obtained by adding phosphor heattransfer bump-factor uncertainty algorithms to the MAP3D code, resulting in global uncertainty surface maps similar to the three-dimensional heat transfer maps. The process is outlined below.

The solution of the heat conduction equation (i.e. the data reduction equation) used in the IHEAT code is given by

$$
\frac{\Theta_{w}}{h_{a w}\left(T_{w} / i_{w}\right)-T_{\text {init }}}=1-e^{\Lambda^{2}} \operatorname{erfc} \Lambda
$$

where

$$
\Theta(x, y, t)=T(x, y, t)-T_{i n i t}(x, y, 0) \text { and } \Lambda=\frac{h\left(h_{w} / T_{w}\right) \sqrt{t}}{\beta}
$$

Also, $h$ is the convective heat transfer coefficient, $h_{a w}$ is the adiabatic wall enthalpy, $h_{w}$ is the wall enthalpy, $T_{w}$ is the corresponding wall temperature, and $t$ is the effective time of data acquisition. $\beta$ is the thermal product of the substrate materials and it is the square root of the product of the material density, specific heat, and thermal conductivity. Bias and precision uncertainty values developed at the 95 percent confidence level for each parameter appearing in the data reduction equation are given in Table 12.

Table 12.- Variable uncertainty values.

\begin{tabular}{|l|c|c|}
\hline \multicolumn{1}{|c|}{ Uncertainty Type } & $\begin{array}{c}\text { Bias } \\
\text { Uncertainty Value }\end{array}$ & $\begin{array}{c}\text { Precision } \\
\text { Uncertainty Value }\end{array}$ \\
\hline Initial model wall temperature & $1.43{ }^{\circ} \mathrm{C}$ & $1.0{ }^{\circ} \mathrm{C}$ \\
Model run wall temperature at reference location & $1.93{ }^{\circ} \mathrm{C}$ & $\mathrm{n} / \mathrm{a}$ \\
Model run wall temperature & $3.36{ }^{\circ} \mathrm{C}$ & $1.0{ }^{\circ} \mathrm{C}$ \\
Effective time & $0.02 \mathrm{~s}$ & $0.05 \mathrm{~s}$ \\
Thermal properties & $5.9 \%$ & $\mathrm{n} / \mathrm{a}$ \\
\hline
\end{tabular}

Each of these individual parameter uncertainties was individually inserted into the data reduction equation to determine a component uncertainty in heat transfer coefficient. The bias uncertainty, $B$, and the precision uncertainty, $P$, for the heat transfer coefficient were determined by obtaining the root-sum-square (RSS) from each of the component uncertainties using

$$
B=\left(\sum_{j} B_{j}{ }^{2}\right)^{1 / 2} \text { and } P=\left(\sum_{j} P_{j}^{2}\right)^{1 / 2}
$$

where $j$ is the number of component uncertainties. Total uncertainties are obtained by taking the RSS of the bias and precision uncertainties. Bias and total uncertainties of the heat transfer coefficients are determined at every pixel point imaged on the model.

Bump factors extracted from the mappings were used in two ways: 1) as line cuts when selecting specific data, and 2) as regions of interest over which all of the data were averaged. In the first case, the total uncertainties are applicable and in the latter, bias uncertainties are applicable. Precision uncertainties are removed during averaging, since they are primarily due to random pixel scatter. Accordingly, the average heat transfer coefficient $h_{\text {avg }}$ used to compute bump factors was assumed to have only a bias uncertainty. Typically, total uncertainties are determined using the quotient rule by adding the total uncertainty in $\mathrm{h}_{\text {local }}$ to the bias uncertainty in $\mathrm{h}_{\text {avg. }}$. For nominally flat models of this type, very low heating rates are obtained during a run and the resulting uncertainties were initially very high. Yet, comparisons of line cuts were more consistent than the uncertainty analysis seemed to suggest. While conservatism is important, excessive conservatism is undesirable. Therefore, the phosphor temperature lookup table data were re-examined and it was determined that since there was minimal variation of incident UV intensities on the models during the tunnel runs, and because of the low heating measurements, the data were typically confined to one very small segment of the temperature range. Thus, the bias uncertainties for the data used in calculating $\mathrm{h}_{\text {local }}$ and $\mathrm{h}_{\text {avg }}$ were uni-directional and determinate. Therefore, the bias uncertainties in $\mathrm{h}_{\text {local }}$ had to be subtracted from the bias uncertainties in $\mathrm{h}_{\text {avg }}$ via the quotient rule, instead of added, when computing bias 
uncertainties for the augmentation factors. Similarly, total uncertainties in augmentation factors were then obtained simply by taking the RSS of the bias and precision uncertainties in $\mathrm{h}_{\text {avg }}$ and by subtracting the bias uncertainties in $\mathrm{h}_{\text {local }}$.

Representative bias uncertainties for Run 63 , an open cavity $(\mathrm{L} / \mathrm{H}=7.2, \mathrm{H} / \delta=1.14)$ on the expansion plate, are shown in Figure 12a, corresponding total uncertainties are shown in Figure 12b. This cavity represents one of the more challenging measurement configurations from an accuracy standpoint because the flow does not directly enter the cavity, resulting in a very small floor temperature rise relative to the pre-run condition. Here, total and bias uncertainties are typically less than $10 \%$ over the plate surface. In the cavity where the lowest temperatures are experienced, the bias uncertainties are about $10 \%$, while the total uncertainties approach $20 \%$.

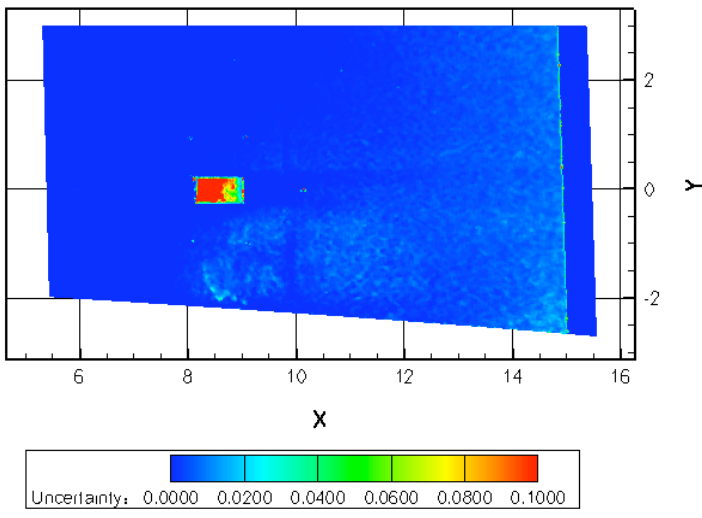

a) Bias uncertainties (\% Uncertainty/100).

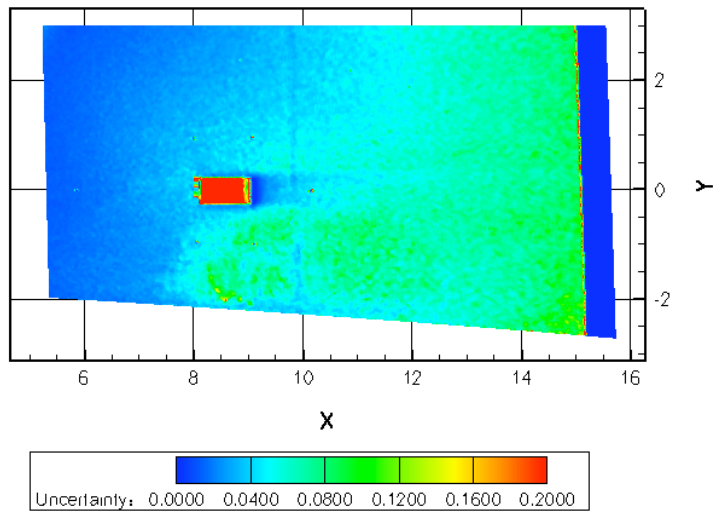

b) Total uncertainties (\% Uncertainty/100).

Figure 12.- Expansion model bump factor uncertainties for Run $63-\mathrm{L} / \mathrm{H}=7.2, \mathrm{H} / \delta=1.14$.

\section{Results}

The objective of the present paper is to address whether pressure gradient has an impact on the augmentation of cavity-induced heating. The results presented here represent a preliminary evaluation of the data based solely a qualitative examination of the centerline BF distributions that are presented in Figure 13 and Figure 14. In each case, the scaled and normalized distribution data are presented with the cavity entrance at $\left(\mathrm{x}-\mathrm{x}_{\text {cav }}\right) / \mathrm{H}=0$. The cavity end wall occurs nominally at $\left(\mathrm{x}-\mathrm{x}_{\text {cav }}\right) / \mathrm{H}=7.2$ for the short (open) cavities and $\left(\mathrm{x}-\mathrm{x}_{\text {cav }}\right) / \mathrm{H}=20$ for the long (closed) cavities. The sharp spikes in the data upstream and downstream of the cavity are the disturbances caused by the previously mentioned fiducial markings on the model. Normally, these fiducial marks would be filtered out of the data, but they have been left in to indicate the quality of the data alignment that occurs during translation and scaling processes.

Considering the short cavity cases first (Fig. 13), flow remains laminar for all the runs with the expansion model; however, runs 52 and 53 with the flat plate model appear non-laminar upon exiting the cavity. The favorable pressure gradient provided by the expansion plate offers some relief to the susceptibility of the short cavity to boundary layer transition. When transitional flow is observed downstream a different, elevated heating profile occurs inside the cavity, most likely because of a more energetic shear layer over the cavity, increasing the cavity mass interchange with the hotter main stream. Not unexpectedly, little difference is seen in the distributions when these cases are excluded, because the flow physics implies that the external stream skips the cavity.

After first excluding transitional/turbulent runs 41, 42, and 43 occurring on the flat plate, the long cavity distributions presented in Figure 14 yield a different conclusion. For long (closed) cavities, the flow will enter the cavity. Since the pressure in the expansion model is dropping below that of the flat plate model, it is anticipated that the turning of the flow into the cavity will be greater and that vortical interactions will be increased. Figure 14a supports this conclusion based on the augmented heating levels on the floor of the cavity compared to the zeropressure gradient cavity shown in Figure 14b. Similarly downstream of the expansion cavity, the increased vorticity in the flow elevates the shearing at the surface and augments the centerline heating above that experienced by the zero-gradient cavity. However, a fair comparison requires further global image analysis to establish whether the flow exiting the long expansion cavities has remained laminar. 


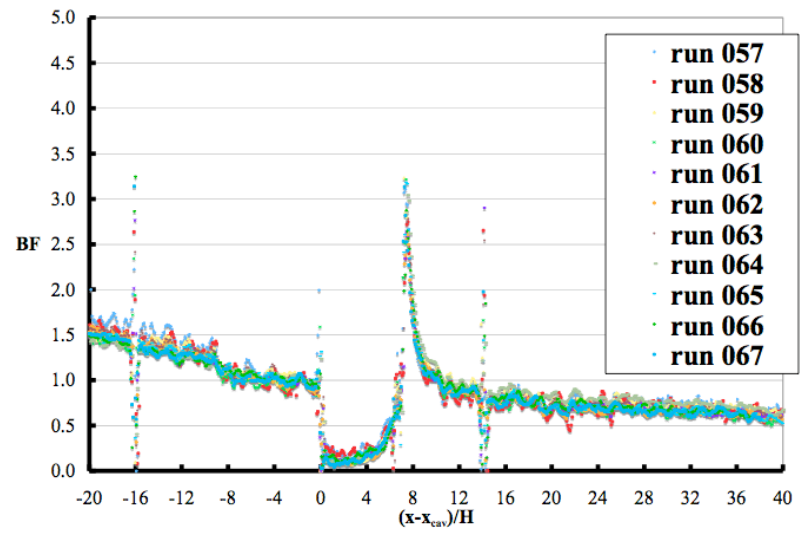

13a- Expansion model.

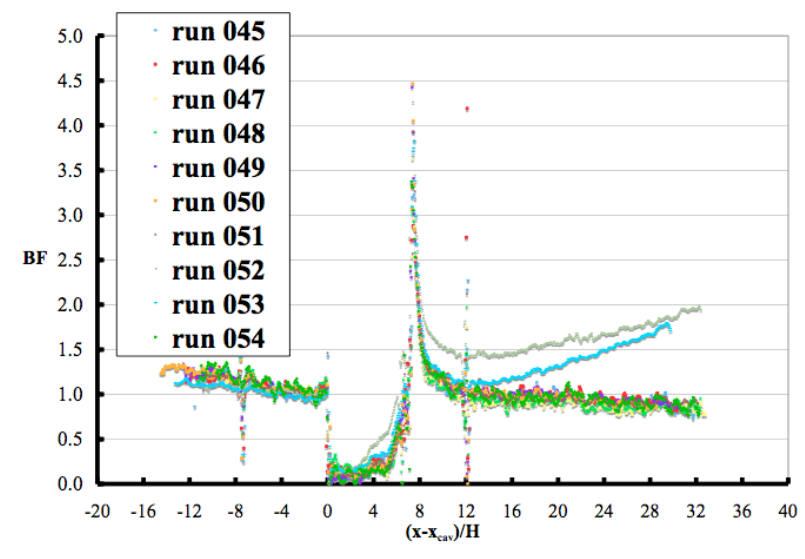

13b) Flat model.

Figure 13.- Centerline bump factor distributions for $L / H=7.2$ models.

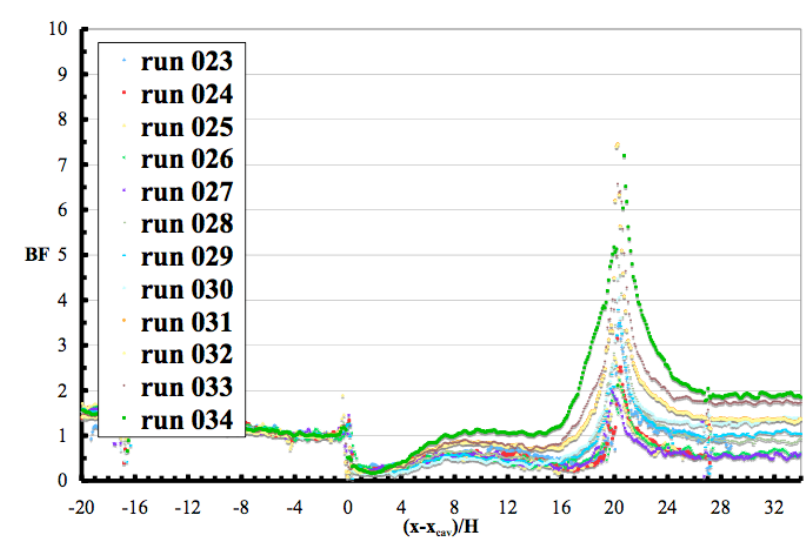

14a) Expansion model.

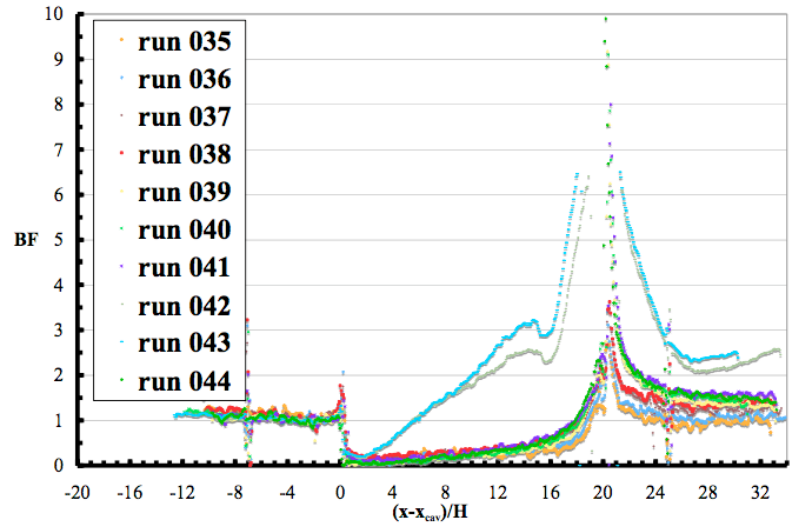

14b) Flat plate model.

Figure 14.- Centerline bump factor distributions for $L / H=20$ models.

A more quantitative assessment can be obtained by averaging the floor data between $0.5 \leq\left(\mathrm{x}-\mathrm{x}_{\text {cav }}\right) / \mathrm{H} \leq 6$ for the short cavities and between $0.5 \leq\left(\mathrm{x}-\mathrm{x}_{\mathrm{cav}}\right) / \mathrm{H} \leq 18$ for the long cavities to create $\mathrm{BF}_{\text {avg. }}$. These limits are selected to remove the upstream and downstream end wall effects on the data. The variation of $\mathrm{BF}_{\text {avg }}$ with pressure gradient is presented in Figure 15. The circles represent the long cavity; squares represent the short cavity; and, filled symbols represent the nominally zero pressure gradient conditions on the flat plate model. Considering first the short cavities (squares), $\mathrm{BF}_{\mathrm{avg}}$, the floor heating augmentation, is roughly $20 \%$ of the nominal undisturbed surface heating, irregardless of the pressure gradient. The long cavities (circles), on the other hand, have a distinct pressure gradient effect with the average heating on the cavity floor being about $30 \%$ of the reference for low-pressure gradients and

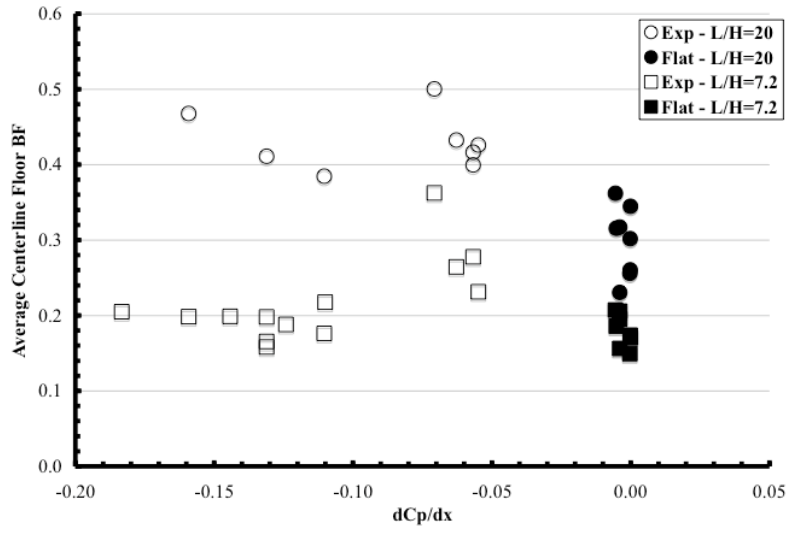

Figure 15.- Variation of average centerline floor bump factor with pressure gradient. 
increasing to nearly $50 \%$ as the pressure gradient increases. Note that this increase is above the previously cited uncertainty level.

Figure 16 presents the variation of the maximum end wall bump factor, $\mathrm{BF}_{\max }$, as an additional pressure-gradient assessment metric. All runs, including those presumed transitional/turbulent have been included. No clear discernable trend with pressure gradient is apparent here for either the short or long cavity, but a large jump in the magnitude from the 3-to-5 range to the 8-to-10 range does occur for the long-cavity zero-gradient test conditions where transitional/turbulent flow is presumed (runs 41, 42, and 43). Plotting the $\mathrm{BF}_{\max }$ variation with $\mathrm{H} / \delta$ offers no additional clarity; however, if the variation is plotted with $\mathrm{L} / \delta$ (Fig. 17), then the step change occurs for $L / \delta>25$. Though not complete as a correlation parameter, $\mathrm{L} / \delta$ is a clear indicator of cavity-induced transition/turbulence onset for those cavities installed on the flat plate. An examination of the traditional boundary layer correlation parameter, $\mathrm{Re}_{\theta} / \mathrm{M}_{\mathrm{e}}$, found in Table 4 and Table 5 also indicates that these represent the largest values obtained during the experiment, and according to unpublished, ongoing independent work, they are in the range where transition can be expected. Further analysis of the image data and correlation with additional data are required before any definitive expression can be made regarding the effect of pressure gradient on $\mathrm{BF}_{\max }$.

\section{Conclusion}

An experiment to evaluate the possible influence of pressure gradient on the heating augmentation induced by rectangular cavities has been conducted in support of the Space Shuttle Return-to-Flight Program. Two-dimensional viscous computational solutions via the LAURA code were used to design a rectangular-planform expansion-plate model, yielding a longitudinal gradient typical of what would be

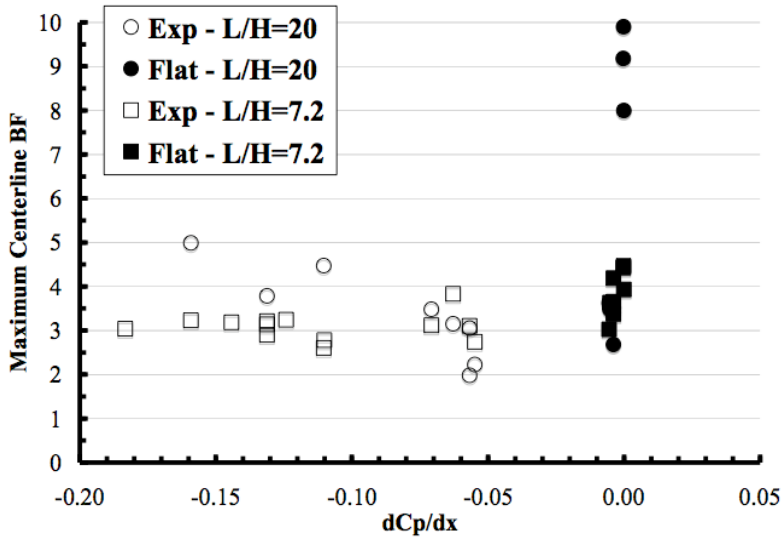

Figure 16.- Variation of maximum centerline bump factor with pressure gradient.

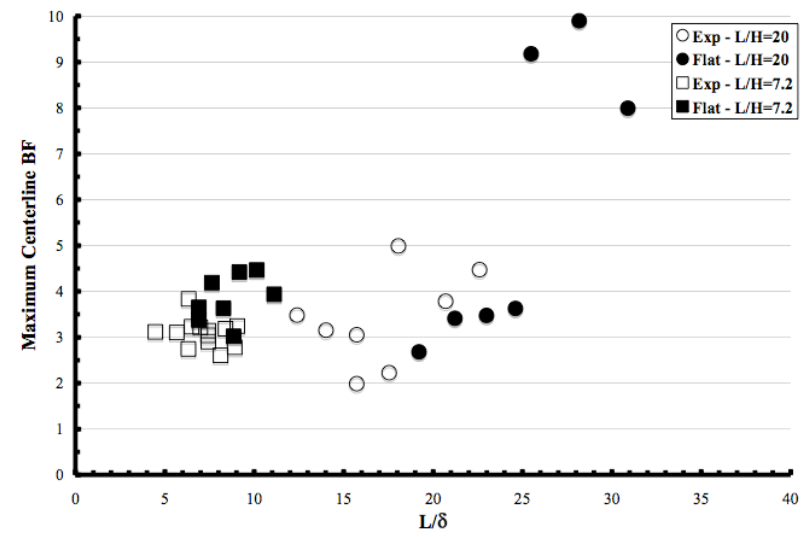

Figure 17. Variation of maximum centerline bump factor with $L / \delta$. experienced on the chine region of the shuttle orbiter.

Three-dimensional viscous solutions were used to evaluate the centerline pressure gradient as a check on the design process. Using the two-dimensional simulations of the expansion plate model and a corresponding flat plate model, predicted boundary layer edge conditions were used to design open $(\mathrm{L} / \mathrm{H}=7.2, \mathrm{~W} / \mathrm{H}=3.6, \mathrm{H} / \delta=1.1)$ and closed $(\mathrm{L} / \mathrm{H}=20, \mathrm{~W} / \mathrm{H}=3.6, \mathrm{H} / \delta=1.1$ ) cavities for each model. Four ceramic cavity models (one for each cavity) were manufactured and the two-color phosphor thermography method was used to determine the global heating distribution on each. The test parameters and image data have been presented for completeness. Centerline distributions normalized to bump factor (or heating augmentation factor) format have been analyzed to assess the existence of a pressure gradient effect. For the short (open) cavity geometries, pressure gradient was found to have minimal effect, if any, on the average floor heating augmentation. In this case, all floor averages scattered around a nominal value of 0.2 . For the long (closed) cavity geometries, pressure gradient increased the average heating augmentation factor by $50 \%$ on average above the zero gradient conditions, which was approximately 0.3 . An assessment of the maximum augmentation on the end wall revealed no apparent effect for the short cavity; however, the analysis was inconclusive for the long cavity, requiring additional image and correlation analysis. 


\section{Acknowledgment}

The authors gratefully acknowledge the contributions of Mr. Gary Wainwright for the design and fabrication of the sterolithography models, Mr. Mark Griffith and Mr. Michael Powers for fabrication of the ceramic models, Mrs. Kathy Kuykendall, Mr. Peter Veneris, and Mr. Ed Covington for the quality assurance measurements, Mr. Kevin Hollingsworth for engineering contributions during the test, and Mr. Andrew J. Hyatt for mapping the test data.

\section{References}

Adams, J.C., Jr.: "Numerical Calculation of Hypersonic Laminar Cavity Flows," AIAA Paper 74-707, ASME 74-HT-27, AIAA/ASME 1974 Thermophysics and Heat Transfer Conference, Boston, Mass., July 1974.

Blair, A.B., Jr. and Stallings, R.L., Jr.: "Supersonic Axial-Force Characteristics of a Rectangular-Box Cavity with Various Length-to-Depth Ratios in a Flat Plate,” NASA TM-87659, 1986.

Boerrigter, Herman and Charbonnier, Jean-Marc: "Roughness-induced transition in hypersonic flow," Space Scientific Research in Belgium, Volume 4; 51-52; D/1996/1191/5-Vol-4/ (SEE 19970005230)

Buck, G.M., and Vasques, P.: "An Investment Ceramic Slip-Casting Technique for Net-Form, Precision, Detailed Casting of Ceramic Models,” U.S. Patent 5,266,252, November 1993.

Buck, G.M., Powers, M.A., Nevins, S.C., Griffith, M.S., Verneris, P.H., and Wainwright, G.A.: "Rapid Fabrication of Flat Plate Cavity Phosphor Thermography Test Models for Shuttle Return-to-Flight Aero-Heating," NASA/TM-2006 (Submitted for Publication).

Burggraf, O.R.: "A Model of Steady Separated Flow in Rectangular Cavities at High Reynolds Number," Proceedings of the 1965 Heat Transfer and Fluid Mechanics Conference, Stanford University Press, 1965, pp. 190-229.

Carlson, W.O.: "A Solution to Heat Transfer in Laminar Separated and Wake Flow Regions," General Electric R59 SD-356, March 1959.

Chang, P.K.: "The Reattachment of Laminar Cavity Flow with Heat Transfer at Hypersonic Speed," AFOSR-66-0135, 1966.

Chapman, D.: "A Theoretical Analysis of Heat Transfer in Separated Flow," NACA TN-3792, October 1956.

Charbonnier, J.-M., and Boerrigter, H.L.: "Contribution to the study of gap induced boundary layer transition in hypersonic flow," AIAA Paper 93-5111, presented at AIAA and DGLR, 5th International Aerospace Planes and Hypersonic Technologies Conference, Munich, Germany, November 30-December 3, 1993.

Charwat, A.F., Roos, J.N., Dewey, C.F., Jr., and Hitz, J.A.: "An Investigation of Separated Flows - Part I: The Pressure Field," Journal of Aerospace Sciences, Vol. 28, No. 6, June 1961, pp. 457-470.

Charwat, A.F., Dewey, C.F., Roos, J.N., and Hitz, J.A.: "An Investigation of Separated Flows - Part II: Flow in the Cavity and Heat Transfer," Journal of Aerospace Sciences, Vol. 28, No. 7, pp. 513-527, July 1961.

Chin, E., Rafiinejad and Seban, R.A.: "Prediction of the Flow and Heat Transfer in a Rectangular Wall Cavity with Turbulent Flow," Transactions of the ASME, Journal of Applied Mechanics, Vol. 39, Series E, No. 2, pp. 351-358, June 1972.

Cheatwood, F. McNeil, Merski, N. Ronald, Jr., Riely, Christopher J., and Mitcheltree, Robert A.: "Aerothermodynamic Environment Definition for the Genesis Sample Return Capsule," AIAA 2001-2889, Presented at 35th AIAA Thermophysics Conference, Anaheim, CA, June 11-14, 2001.

Coats, Jack D., Rhudy, R.W., and Edmunds, E.W.: "Effects of Surface Gaps and Steps on Laminar Heat-Transfer Rates at Local Mach Numbers from 3 to 10," AEDC-TR-70-17, February 1970.

Dye, Thomas P., Everhart, Joel L., Hodge, J.A.: "Blockage Induce by Large Test Technique Demonstrator Models with Propulsion Simulation in the NASA Langley 31-Inch Mach 10 Tunnel,” NASP Technical Memorandum 1163, 1992.

Emery, A.F.: "Recompression Step Heat Transfer Coefficients for Supersonic Open Cavity Flow," Journal of Heat Transfer, 1969, pp. 168-170.

Fay, J.A. and Riddell, F.R.: "Theory of Stagnation Point Heat Transfer in Dissociated Air," Journal of Aeronautical Sciences, Vol. 25, No. 2, 1958, pp. 73-85.

Fletcher, L.S., Briggs, D.G., and Page, R.H.: “A Review of Heat Transfer in Separated and Reattached Flows," AIAA-70767, July 1970.

Galenter, S.A.: "An Experimental Summary of Plasma Arc Exposures of Space Shuttle High-Temperature Reusable Surface Insulation Tile Array with a Single Missing Tile (Conducted at the Ames Research Center)," NASA SP-379, Paper 18, 1975.

Gnoffo, P.A., Gupta, R.N., and Shinn, J.L.: "Conservation Equations and Physical Models for Hypersonic Air Flows in Thermal and Chemical Nonequilibrium," NASA TP 2867, February 1989.

Gnoffo, P.A.: An Upwind-Biased, Point-Implicit Relaxation Algorithm for Viscous, Compressible Perfect Gas Flows," NASA TP 2953, February 1990.

Hahn, Mansop: "Experimental Investigation of Separated Flows over a Cavity at Hypersonic Speed," AIAA No. 68-672, AIAA Journal, Vol. 7, No. 6, June 1969, pp. 1092-1098.

Hollis, B.R.: "Real-Gas Flow Properties for NASA Langley Research Center Aerothermodynamic Facilities Complex Wind Tunnels," NASA CR 4755, September 1996.

Hollis, Brian R. and Liechty, Derek S.: "Boundary Layer Transition Correlations and Aeroheating Predictions for Mars Smart Lander," AIAA 2002-2745, Presented at 32nd AIAA Fluid Dynamics Conference and Exhibit, St. Louis, Missouri, 24-26 June 2002. 
Hollis, Brian R. and Liechty, Derek S.: "Correlations for Boundary Layer Transition on Mars Science Laboratory Entry

Vehicle due to Heat-Shield Cavities," NASA/TP-2006 (Submitted for Publication).

Hunt, L.R.: "Aerodynamic Heating and Loading within Large Open Cavities in Cone and Cone-Cylinder-Flare Models at Mach 6.7," NASA TN D-7403, March 1974.

Hunt, L.R.: "Aerodynamic Heating in Large Cavities in an Array of RSI Tiles," NASA TN D-8400, 1977.

Johnson, C.B.: "Heat Transfer Data to Cavities between Simulated RSI Tiles at Mach 8," NASA CR 128770, June 1973.

Lamb, J.P.: “An Approximate Theory for Developing Turbulent Free Shear Layers," Trans. ASME, Series D. Vol. 89, No. 3, 1967, pp. 633-642.

Lamb, J.P. and Bass, R.L.: "Some Correlations of Theory and Experiment for Developing Turbulent Free Shear Layers," Trans. ASME, Series D, Vol. 90, No. 4, pp. 572-580, 1968.

Lamb, J.P.: "Convective Heat Transfer Correlations for Planar, Supersonic, Separated Flows", Trans. ASME, Series C, Vol. 102, No. 2, May 1980, pp. 351-356.

Lamb, J.P.: "Analysis and Correlation of Convective Heat Transfer Measurements for Open Cavities in Supersonic Flow," AIAA 80-1526, July 1980.

Larson, H.K. and Keating, Jr., S.L.: "Transition Reynolds Numbers of Separated Flows at Supersonic Speeds," NASA TN D349, December 1960.

Liechty, Derek S., Berry, Scott A., Hollis, Brian R., and Horvath, Thomas J.: "Comparison of Methods for Determining Boundary Layer Edge Conditions for Transition Correlations," AIAA Paper No 2003-3590, Presented at 33rd AIAA Fluid Dynamics Conference and Exhibit, Orlando, FL, June 23-26, 2003.

Liechty, Derek S., Horvath, Thomas J., and Berry, Scott A.: "Shuttle Return to Flight Experimental Results: Cavity Effects on Boundary Layer Transition," NASA TM 2006a (Submitted for Publication).

Liechty, Derek S., Berry, Scott A., and Horvath, Thomas J.: "Shuttle Return to Flight Experimental Results: Protuberance Effects on Boundary Layer Transition," NASA TM 2006b (Submitted for Publication).

Merski, N.R.: "Global Aeroheating Wind Tunnel Measurements Using Improved Two-Color Phosphor Thermography Method," Journal of Spacecraft and Rockets, Vol. 36, No. 2, 1999, pp. 160-170.

Merski, N.R.: "An Improved Two-Color Relative-Intensity Phosphor Thermography Method for Hypersonic Wind Tunnel Aeroheating Measurements,” NASA CDTP-1017, February 2001.

Micol, J.R.: "Hypersonic Aerodynamic/Aerothermodynamic Testing Capabilities at Langley Research Center: Aerothermodynamic Facilities Complex,” AIAA Paper 95-2107, June 1995.

Morgenstern, A. and Chokani, N.: "Hypersonic Flow Past Open Cavities," AIAA Journal, Vol. 32, pp. 2387-2393, 1994. (Computational).

Nestler, D.E.: "Laminar Heat Transfer to Cavities in Hypersonic Low Density Flow," Proceedings 3rd International Heat Transfer Conference, Chicago, IL, Vol. 2, 1966.

Nestler, D.E., Saydah, A.R., and Auxer, W.L.: "Heat Transfer to Steps and Cavities in Hypersonic Turbulent Flow," AIAA Paper No. 68-673, 1968.

Nestler, D.E., Saydah, A.R., and Auxer, W.L.: "Heat Transfer to Steps and Cavities in Hypersonic Turbulent Flow," AIAA Journal, Vol. 7, No. 7, July 1969, pp. 1368-1370.

Nestler, D.E.: "Hypersonic Boundary Layers and Selected Heat Flux Problems," Short Course on Technology of Space Shuttle Vehicles and Space Stations at the University of Tennessee Space Institute, April 1970.

Nestler, D.E.: "Hypersonic Laminar Cavity Heat Transfer," Presented at 4th International Heat Transfer Conference, August 31-September 5, 1970, Versailles, France.

Nestler, D.E.: “An Engineering Analysis of Reattaching Shear Layer Heat Transfer," AIAA Paper 72-717, Presented at 5th AIAA Fluid and Plasma Dynamics Conference, Boston, Mass., June 26-28, 1972.

Nestler, D.E.: "An Experimental Study of Cavity Flow on Sharp and Blunt Cones at Mach 8," AIAA-81-0335, AIAA 19th Aerospace Sciences Meeting, St. Louis, Missouri, January 12-15, 1981.

Nestler, D.E.: "The Effects of Surface Discontinuities on Convective Heat Transfer in Hypersonic Flow," AIAA Paper 850971, AIAA 20th Thermophysics Conference, Williamsburg, VA, June 1985.

Netterfield, M.P. and Hilier, R.: "Experiment and computation in hypersonic cavity flows," AIAA Paper 89-1842, Presented at, $20^{\text {th }}$ AIAA Fluid Dynamics, Plasma Dynamics and Lasers Conference, Buffalo, NY, June 12-14, 1989.

Nicoll, K.M.: "An Experimental Investigation of Laminar Hypersonic Cavity Flows Part II: Heat Transfer and Recovery Factors Measurements," ARL 63-73.

Nicoll, K.M.: “A Study of Laminar Hypersonic Cavity Flows,” AIAA Journal, Vol. 2, No. 9, September 1964.

Pulsonetti, M. and Thompson, R.: "LAURA Aerothermodynamic Computations for Space Shuttle Columbia STS-107

Baseline and Damage Scenarios," AIAA Paper 2004-2278, Presented at 37th AIAA Thermophysics Conference, Portland OR, June 28-July 1, 2004.

Pulsonetti, M.V. and Wood, W.A.: "Computational Aerothermodynamic of Space Shuttle Orbiter Tile Damage - Open Cavities", AIAA-2005-4679, 38th AIAA Thermophysics Conference, Toronto, Canada, June 6-9, 2005.

Reuther, J., McDaniel, R., Brown, J.,Prabhu, D., and Saunders, D.: "External Computational Aerothermodynamic Analysis of the Space Shuttle Orbiter at STS-107 Flight Conditions," $37^{\text {th }}$ AIAA Thermophysics Conference, Portland, OR, June 28-1, 2004.

Rhudy, J.P. and Magnan, Jr., J.D.: "Investigation of Heat-Transfer Distribution in Several Cavity and Step Configurations at Mach 10," AEDC Technical Documentary Report No. AEDC-TDR-64-220, October 1964. 
Shchukin, V.K., Gortyshov, Yu. F., Varfolomeev, I.M., and Nadyrov, N.A.: "Influence of Relative Depth and Reynolds Number on Heat Transfer in Cavities in Compressible Gas Flow," Soviet Aeronaut., Vol. 23, No. 3, 1980, pp. 83-86.

Stallings, Robert L., Jr. and Wilcox, Floyd J., Jr.: "Experimental Cavity Pressure Distributions at Supersonic Speeds", NASA TP 2683, June 1987.

Stallings, Robert L., Jr., Wilcox, Floyd J., Jr., and Forrest, Dana K.: "Measurements of Forces, Moments, and Pressures on a Generic Store Separating From a Box Cavity at Supersonic Speeds,” NASA TP 3110, September 1991.

Throckmorton, D.A.: "Heat Transfer to Surface and Saps of RSI Tile Arrays in Turbulent Flow at Mach 10.3," NASA-TMX-71945, April 1974.

Weinstein, Irving, Avery, Don E., and, Chapman Andrew J.: "Aerodynamic Heating to the Gaps and Surfaces of Simulated Reusable-Surface-Insulation Tile Arrays in Turbulent Flow at Mach 6.6," NASA TM X-3225, November 1975.

Wilcox, Floyd J., Jr.: "Experimental Investigation of Porous-Floor Effects on Cavity Flow Fields at Supersonic Speeds," NASA TP 3032, November 1990.

Wilcox, Floyd J., Jr.: "Tangential, Semi-submerged, and Internal Store Carriage and Separation at Supersonic Speeds," AIAA Paper 91-0198, Presented at 29th Aerospace Sciences Meeting, Reno NV., January 1991 (Cavity passive-venting effects.)

Wood, William A., Pulsonetti, Maria V., Everhart, Joel L., and Bey, Kim S.: "Assessment of Laura for Laminar Supersonic Shallow Cavities," Presented at 34th AIAA Fluid Dynamics Conference, Portland OR, June 28-July 1, 2004.

Wright, M.J., Candler, G., and Bose, D.: "Data-Parallel Line Relaxation Method for the Navier-Stokes Equations," AIAA Journal, Vol. 36, No. 9, 1998, pp. 1603-1609.

Wyborny, W., Kabelitz, H.P. and Schepers, H.J.: "Hypersonic Investigation on the Local and Average Heat Transfer in Cavities and after Steps of Bodies of Revolution," AGARD Conference Proceedings No. 19, Fluid Physics of Hypersonic Wakes, 1967.

Zhang, J., Morishita, E., Okunuki, T., and Itoh H.: "Experimental and Computational Investigation of Supersonic Cavity Flows," AIAA Paper 2001-1755, Presented at AIAA/NAL-NASDA-ISAS 10th International Space Planes and Hypersonic Systems and Technologies Co. 